\title{
Technical note: Intercomparison of three AATSR Level 2 (L2) AOD products over China
}

\author{
Yahui Che ${ }^{1,6}$, Yong Xue ${ }^{1,2}$, Linlu Mei ${ }^{3}$, Jie Guang ${ }^{3}$, Lu She ${ }^{1,6}$, Jianping Guo ${ }^{4}$, Yincui Hu ${ }^{5}$, Hui Xu ${ }^{3}$, Xingwei He ${ }^{1,6}$, \\ Aojie Di ${ }^{1,6}$, and Cheng Fan ${ }^{1,6}$ \\ ${ }^{1}$ State Key Laboratory of Remote Sensing Science, jointly sponsored by the Institute of Remote Sensing and Digital Earth of \\ the Chinese Academy of Sciences and Beijing Normal University, Institute of Remote Sensing and Digital Earth, \\ Chinese Academy of Sciences, 100101 Beijing, China \\ ${ }^{2}$ Department of Computing and Mathematics, College of Engineering and Technology, University of Derby, \\ Kedleston Road, Derby, DE22 1GB, UK \\ ${ }^{3}$ Key Laboratory of Digital Earth Science, Institute of Remote Sensing and Digital Earth, Chinese Academy of Sciences, \\ 100094 Beijing, China \\ ${ }^{4}$ Centre for Atmosphere Watch and Services, Chinese Academy of Meteorological Sciences, 46 Zhongguancun South \\ Avenue, Haidian District, 100081 Beijing, China \\ ${ }^{5}$ Hebei Key Laboratory of Environmental Change and Ecological Construction, College of Resources and Environment \\ Science, Hebei Normal University, Shijiazhuang, Hebei Province, China \\ ${ }^{6}$ University of Chinese Academy of Sciences, 100049 Beijing, China
}

Correspondence to: Yong Xue (yx9@ hotmail.com)

Received: 5 March 2016 - Published in Atmos. Chem. Phys. Discuss.: 16 March 2016

Revised: 29 June 2016 - Accepted: 3 July 2016 - Published: 2 August 2016

\begin{abstract}
One of four main focus areas of the PEEX initiative is to establish and sustain long-term, continuous, and comprehensive ground-based, airborne, and seaborne observation infrastructure together with satellite data. The Advanced Along-Track Scanning Radiometer (AATSR) aboard ENVISAT is used to observe the Earth in dual view. The AATSR data can be used to retrieve aerosol optical depth (AOD) over both land and ocean, which is an important parameter in the characterization of aerosol properties. In recent years, aerosol retrieval algorithms have been developed both over land and ocean, taking advantage of the features of dual view, which can help eliminate the contribution of Earth's surface to top-of-atmosphere (TOA) reflectance. The Aerosol_cci project, as a part of the Climate Change Initiative (CCI), provides users with three AOD retrieval algorithms for AATSR data, including the Swansea algorithm (SU), the ATSR-2ATSR dual-view aerosol retrieval algorithm (ADV), and the Oxford-RAL Retrieval of Aerosol and Cloud algorithm (ORAC). The validation team of the Aerosol-CCI project has validated AOD (both Level 2 and Level 3 products) and AE (Ångström Exponent) (Level
\end{abstract}

2 product only) against the AERONET data in a roundrobin evaluation using the validation tool of the AeroCOM (Aerosol Comparison between Observations and Models) project. For the purpose of evaluating different performances of these three algorithms in calculating AODs over mainland China, we introduce ground-based data from CARSNET (China Aerosol Remote Sensing Network), which was designed for aerosol observations in China. Because China is vast in territory and has great differences in terms of land surfaces, the combination of the AERONET and CARSNET data can validate the L2 AOD products more comprehensively. The validation results show different performances of these products in 2007, 2008, and 2010. The SU algorithm performs very well over sites with different surface conditions in mainland China from March to October, but it slightly underestimates AOD over barren or sparsely vegetated surfaces in western China, with mean bias error (MBE) ranging from 0.05 to 0.10 . The ADV product has the same precision with a low root mean square error (RMSE) smaller than 0.2 over most sites and the same error distribution as the SU product. The main limits of the ADV algorithm are 
underestimation and applicability; underestimation is particularly obvious over the sites of Datong, Lanzhou, and Urumchi, where the dominant land cover is grassland, with an MBE larger than 0.2, and the main aerosol sources are coal combustion and dust. The ORAC algorithm has the ability to retrieve AOD at different ranges, including high AOD (larger than 1.0); however, the stability deceases significantly with increasing AOD, especially when AOD $>1.0$. In addition, the ORAC product is consistent with the CARSNET product in winter (December, January, and February), whereas other validation results lack matches during winter.

\section{Introduction}

The Pan-Eurasian Experiment (PEEX) is a multidisciplinary, multiscale, and multicomponent research, research infrastructure, and capacity-building program (Kulmala et al., 2015). One of the strategically most important tasks of PEEX is to fill in the observational gap in atmospheric in situ data in the Siberian and Far East region and start the process towards standardized and harmonized data procedures (Kulmala et al., 2011). Aerosols play a major role in Earth's climate system, including intervening in the radiation budget and cloud processes and affecting air quality and human health (Remer et al., 2005; Samet et al., 2000; Tzanis and Varotsos, 2008; Kokhanovsky and de Leeuw, 2009). The particles suspended in the troposphere scatter solar radiation back to cool the atmosphere or absorb solar radiation, which warms the atmosphere, causing changes in the net effect of aerosols. These particles could also affect the formation and microphysical properties of clouds as cloud condensation nuclei (Andreae and Rosenfeld, 2008). The source of aerosols could be anthropogenic or natural (Varotsos et al., 2012). Particles from different sources are mixed into aerosol masses to influence aerosol optical depth (AOD), reduce visibility (Kinne et al., 2003; Varotsos 2005; Remer et al., 2005), and cause spatial and temporal variability of AOD; therefore, the largest uncertainties in the estimation of radiative forcing are introduced by aerosols (IPCC, 2013).

Over the past 35 years, different types of satellites have been used to obtain atmospheric information, especially aerosol properties (Griggs, 1979; Kokhanovsky and de Leeuw, 2009). Remote sensing provides a means to obtain global and long-term observations of aerosols, especially in the widest oceans and remote regions where ground-based stations cannot be constructed. In addition, polar-orbiting satellites and geostationary satellites obtain daily global images, which help to capture changes in aerosol patterns and properties (Prins et al., 1998; Torres et al., 2002). There are, however, many difficulties in observing aerosols by satellites because depending on the surface properties, the contribution to the signal received by the satellite can vary drastically; aerosol components and concentrations are constantly vary- ing, and their sources cannot be precisely determined (Levy et al., 2007).

The Advanced Along-Track Scanning Radiometer (AATSR) aboard ENVISAT is used to observe the Earth in dual view, of which one component is nadir direction and the other is forward direction with a viewing angle of $55^{\circ}$ from nadir view. The AATSR was designed to have seven spectral channels at wavelengths of $0.55,0.67,0.87,1.63$, 10.7 , and $12 \mu \mathrm{m}$. The nadir spatial resolution is $1 \mathrm{~km} \times 1 \mathrm{~km}$ with a swath width of 512 pixels. Furthermore, the AATSR instrument equipped two calibration targets: a black-body calibration target for thermal channels and an opal visible calibration target for visible and near-Infrared channels, aiming to implement self-calibration. The data from AATSR can be used to retrieve AOD both over land and ocean, which is important for the characterization of aerosol properties (Adhikary et al., 2008). In recent years, some aerosol retrieval algorithms have been established both over land and ocean, taking advantage of the features of dual view, which can help eliminate the contribution of surface to top-of-atmosphere (TOA) reflectance. Aerosol_CCI, as part of the Climate Change Initiative (CCI) (http://www.esa-aerosol-cci.org/), provides users with three algorithms for AATSR data, including the Swansea algorithm (SU) (Bevan et al., 2012), the ATSR-2/AATSR dual-view aerosol retrieval algorithm (ADV) (Kolmonen et al., 2015), and the Oxford-RAL Retrieval of Aerosol and Cloud algorithm (ORAC) (Thomas et al., 2009). The aim of this work is to evaluate different performances of these algorithms in calculating AOD over different regions of China in 2007, 2008, and 2010.

A ground-based sun photometer has been used to take sun and sky measurements directly (Holben et al., 1998). The Aerosol Robotic NETwork (AERONET) has constructed hundreds of sites all over the world as of 2015. These stations, operated by the American National Aeronautics and Space Administration (NASA), are operational worldwide, providing multispectral channel validation data for satelliteretrieved data to complete synthetic measurements on a global scale.

The China Aerosol Remote Sensing Network (CARSNET) is a ground-based aerosol monitoring system that uses CE-318 sun photometers, similar to AERONET, and has constructed 37 sites throughout China (Che et al., 2009). It has been established that CARSNET AOD measurements are approximately 0.03, 0.01, 0.01, and 0.01 larger than measurements by AERONET in the 1020, 870,670 , and $440 \mathrm{~nm}$ channels, respectively (Che et al., 2009). In this paper, we combine two aerosol observation datasets from AERONET and CARSNET as reference data to validate these three AATSR AOD products over China more comprehensively.

The basic method for assessment is to compare the retrieval results with data (AOD mainly) obtained by AERONET/CARSNET. However, this direct comparison of retrieval results with AERONET data is limited due to dif- 
ferent cloud screening processes (de Leeuw et al., 2013), and such a limitation could influence the validation reliability to some extent. To make the validation more reliable, comparison of the retrieval results with high-quality data from the Moderate Resolution Imaging Spectroradiometer (MODIS) or Multiangle Imaging Spectroradiometer (MISR) is also an effective method for validation (Kahn et al., 2009). However, AERONET or other ground-based networks provide accurate measurements without the influence of land surface reflection (Holben et al., 1998), which means that comparison of retrieved AOD with ground-based measurements is the basic method. The AATSR L2 products provided by Aerosol_CCI have been validated by the validation team via a round-robin (RR) test (de Leeuw et al., 2013). On this basis, we focused on assessing the performance of AATSR aerosol L2 products in mainland China by comparing the retrieval results with AERONET and CARSNET data.

\section{Reference data and validation statistics}

AOD is the most important parameter in terms of aerosol properties and is different from other retrieved parameters in the Aerosol_CCI project. The Aerosol_CCI project adopts three aerosol retrieval algorithms for the ATSR-2/AATSR instrument, including the Swansea algorithm (SU) (Bevan et al., 2012), the ATSR-2/AATSR dual-view aerosol retrieval algorithm (ADV) (Kolmonen et al., 2015), and the OxfordRAL Retrieval of Aerosol and Cloud algorithm (ORAC) (Thomas et al., 2009). All three algorithms are able to retrieve aerosol properties both over land and ocean. The ADV algorithm was originally developed for retrieving AOD properties over land at wavelengths of $0.555,0.659$, and $1.61 \mu \mathrm{m}$ (Veefkind et al., 1998). The main advantage of ADV is the introduction of a k-ratio approach to eliminate the contribution of reflection to TOA reflectance, which uses the ratio of the reflectance measured in the forward and nadir views (Flowerdew and Haigh, 1995). The ORAC algorithm is designed to retrieve AOD properties in each of four AATSR short-wave channels both over land and ocean, including AOD, effective radius, and surface reflectance. The build of the forward model used in the ORAC algorithm is based on the radiative transfer code DISORT. A parameterized model of surface reflectance distribution is used in retrieval and combines with the AATSR dual view to make up for the lack of a priori reflectance (North et al., 1999). An iterative optimization method is employed to determinate AOD, aerosol type, and surface reflectance.

AATSR L2 data (see Table 1) are daily products with a spatial resolution of $10 \times 10 \mathrm{~km}^{2}$, and contain a quality flag or a level of confidence for each pixel (de Leeuw et al., 2013). Compared to the Level 3 (L3) product with a spatial resolution of $1^{\circ} \times 1^{\circ}$, daily $\mathrm{L} 2$ data have a higher spatial resolution, which helps to capture greater detail of aerosol properties and is further explored in our follow-up study/research after this manuscript.

It has been demonstrated that the ground-based observation data from AERONET have the ability and precision to be used as reference data when users validate AOD (Holben et al., 1998). There are 8 AERONET sites in mainland China providing Level 2.0 (L2) data (cloud-screened and qualityassured) for 2007, 11 sites for 2008, and 10 sites for 2010, from which the AOD measurement data are available on the website. However, most of these sites are distributed in the eastern China coastal area, as shown in Fig. 1, which, however, does not meet the requirements of comprehensively validating the aerosol properties over all of China. Substantial hazardous aerosol pollution affects most regions of northern (Li, 2014) and eastern China in winter, and heavy dust aerosols from the Taklimakan Desert in western China can be transported long distances to eastern China, even to Japan (Takahashi, 2011), resulting in regional differences.

The measurements from another network, CARSNET, equipped with calibrated CE-318 instruments, have the same accuracy as AERONET. CARSNET has more sites than AERONET in mainland China, and the spatial distribution of the CARSNET sites is distributed more evenly. Therefore, for the purpose of assessing different performances of these three AATSR L2 AOD products, we selected ground-based measurements from both of these two networks as reference data.

AERONET provides AOD data at three data quality levels: Level 1.0 (unscreened), Level 1.5 (cloud-screened), and Level 2.0 (cloud-screened and quality-assured) (http: //aeronet.gsfc.nasa.gov/new_web/index.html). Here, we selected AERONET L2 data that are screened and qualityassured. Because both the AERONET and CARSNET data are AATSR products without band-effective wavelengths, we interpolated the ground-based data to the $550 \mathrm{~nm}$ wavelength. The AOD of the L2 datasets were compared with AERONET and CARSNET observation data using scatter plots and linear regression of the data. The comparisons were made for collocated satellite and ground-based observations (Ichoku et al., 2002); i.e. AOD pixels were selected from the ground-based measurements within a spatial extent of $\pm 25 \mathrm{~km}$ of ground-based stations and a time range of $\pm 30 \mathrm{~min}$ of the AATSR overpass. At least five AATSR AOD retrievals and two AERONET or CARSNET observations are required in each collocation (Levy et al., 2010).

We conducted collocations according to year $(2007,2008$, and 2010) and dataset (ADV, ORAC, and SU). In total, 20 ground-based observation sites, including 12 AERONET sites and 8 CARSNET sites, were in Chinese territory in 2007, of which 6 AERONET and 8 CARSNET inland sites were selected. For 2008, we selected 8 AERONET and 24 CARSNET inland sites, for a total of 32 sites, ignoring the island sites and those near the shoreline. For 2010, only 6 CARSNET sites are available for us, and a total of 14 in- 


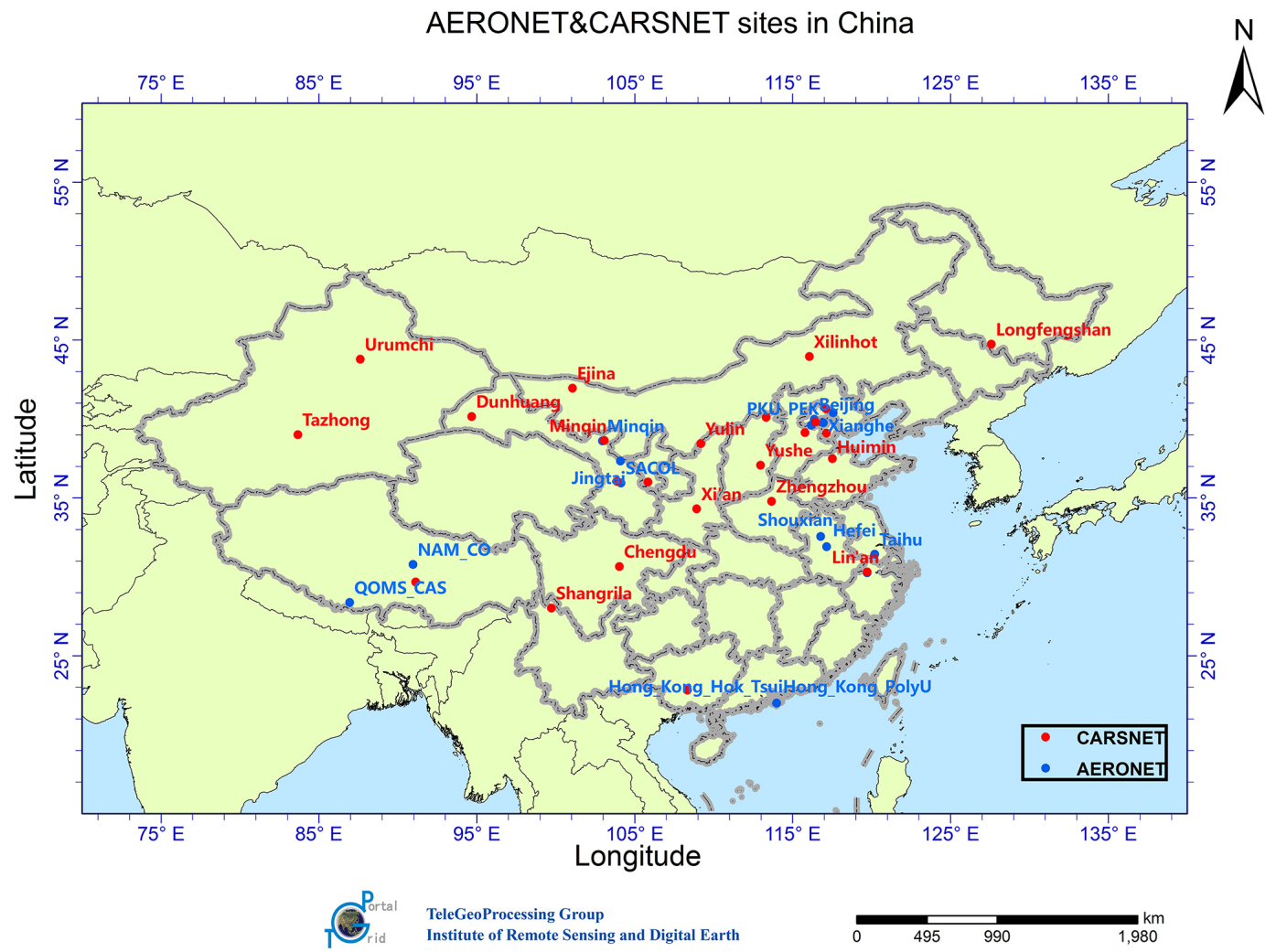

Figure 1. The distribution of selected AERONET and CARSNET sites in mainland China in 2007, 2008, and 2010. The blue and red points represent AERONET and CARNET sites, respectively.

Table 1. Details of AATSR AOD products.

\begin{tabular}{lrlll}
\hline Algorithm & Version & Sensor & Main parameters & Resolution coverage \\
\hline ADV/ASV & 2.3 & AATSR & AOD,ANG & $10 \mathrm{~km}, 1^{\circ}$ global \\
SU & 4.21 & AATSR & AOD, ANG & $10 \mathrm{~km}, 1^{\circ}$ global \\
ORAC & 03.04 & AATSR & AOD, aerosol type & $10 \mathrm{~km}, 1^{\circ}$ global \\
\hline
\end{tabular}

land sites was selected, with 8 AERONET inland sites (see Table 2).

\subsection{Statistical metrics}

Collocated pairs are analysed using statistical methods. Bias describes the average difference between satellite retrievals and ground AOD. Then, to determine how well the satellite data match the ground-based observation data, the relationship between them is explored. Some basic statistics are shown on the scatter plot, including the root mean square error (RMSE):

$\mathrm{RMSE}=\sqrt{\frac{1}{n} \sum_{i=1}^{n}\left(\tau_{\mathrm{sat}, i}-\tau_{\mathrm{aero}, i}\right)^{2}}$,

where $\tau_{\text {aero, } i}$ represents the ground-based observation data and $\tau_{\text {sat }}$ represents the satellite retrievals. Mean satelliteretrieved AOD (MSA) and mean AERONET and CARSNET
Table 2. Selected ground-based sites in China.

\begin{tabular}{llrrrr}
\hline & Network & Inland & $\begin{array}{r}\text { Near } \\
\text { shoreline }\end{array}$ & Island & Total \\
\hline \multirow{2}{*}{2007} & AERONET & 6 & 6 & 0 & 12 \\
& CARSNET & 8 & 0 & 0 & 8 \\
& Total & 14 & 6 & 0 & 20 \\
\hline \multirow{2}{*}{2008} & AERONET & 8 & 7 & 0 & 15 \\
& CARSNET & 24 & 1 & 0 & 25 \\
& Total & 32 & 8 & 0 & 40 \\
\hline \multirow{2}{*}{2010} & AERONET & 8 & 7 & 1 & 16 \\
& CARSNET & 6 & 0 & 0 & 6 \\
\hline & Total & 14 & 7 & 1 & 20 \\
\hline
\end{tabular}


AOD (MAA) represent the central tendency of the data. Relative mean bias (RMB) is used to determine under- or overestimation of the AOD retrievals; it is the ratio of MSA to MAA:

$\mathrm{RMB}=\mathrm{MSA} / \mathrm{MAA}$.

Mean bias error (MBE) is the mean difference between the satellite retrievals and AATSR AODs, and the mean absolute error (MAE) is the absolute value of the mean bias error. Together with RMB, the MBE and MAE are used to determine the magnitude of the difference between the two datasets.

\section{$2.2 \kappa$ statistics}

In the scatter plot of the collocated pairs, the retrieved data and the corresponding collocated ground-based observation data could be considered as two arrays, and the main purpose of KAPPA is to explore how these two arrays match each other. For the retrieval of aerosol properties, the performances of most algorithms decrease in effectiveness with increasing AOD, i.e. difficulties in retrieving AOD will be increased as AOD increases. Obviously, when only using |bias|, the absolute value of the difference between groundbased data and AATSR AOD data in each collocation pair, as an assessment standard for different AODs, is insufficient and lacks persuasion. Therefore, the combination of $|\mathrm{bias}|$ and $\mid$ bias $\mid /$ Ground, i.e. the ratio of $\mid$ bias $\mid$ to the value of the reference data in each collocation pair, used in the KAPPA coefficient will account for this shortage and provide a new statistic for assessing the agreement between two arrays, taking advantage of the KAPPA coefficient.

The KAPPA coefficient was originally proposed as a descriptive statistic indicating the degree of beyond-chance agreement between two ratings per subject in a dichotomous form (Bloch and Kraaemer, 1989). KAPPA coefficients with various forms could also be used to measure the accuracy of thematic classifications (Rosenfield and Fitzpatrick-Lins, 1986). KAPPA is, in short, a measure of "true" agreement (Cohen, 1960). The pairs collocated by matching groundbased data with AATSR L2 AOD data could be regarded as two different arrays so that we introduced the KAPPA coefficient to assess agreement between these two arrays. Based on the concept of the KAPPA coefficient proposed by Cohen (1960), an appropriate modification with a two-category nominal scale is shown in Table 3.

To estimate the KAPPA coefficient, one needs to determine which pairs are true or which pairs are "relevant". However, if only given matched collocation pairs, we cannot determine which pair is relevant. Therefore, the design of criterion 1 and criterion 2 needs to be reasonable and fit for the purpose of validation.

For criterion 1, if |bias $\mid$ is greater than the mean of $\mid$ bias $\mid$, then it is marked as "far from truth", and if not, it is marked as "close to truth". Here, the bias was assessed from the first quartile to the third quartile for eliminating possible "out-
Table 3. Design of the KAPPA coefficient.

\begin{tabular}{llrrr}
\hline & \multicolumn{3}{c}{ Criterion 2 } & Total \\
\cline { 2 - 4 } & & $\begin{array}{r}\text { Relevant } \\
\text { (highly) }\end{array}$ & $\begin{array}{r}\text { Relevant } \\
\text { (low) }\end{array}$ & \\
\hline Criterion 1 & $\begin{array}{l}\text { Relevant } \\
\text { (highly) } \\
\text { Relevant } \\
\text { (low) }\end{array}$ & a & b & G1 \\
\hline Total & c & d & G2 \\
\hline
\end{tabular}

liers". The |bias $\mid$ only indicates the absolute error of the retrieved AOD, and it still needs another statistic for criterion 2 , i.e. $\mid$ bias $\mid /$ Ground, which indicates the relative error of AOD retrieval. For criterion 2, if $\mid$ bias $\mid /$ Ground| is greater than 0.2 , then it is marked as "far from truth", and if not, it is marked as "close to truth". For the conventional formula of calculating the KAPPA coefficient, see

$\mathrm{K}=\frac{P_{\mathrm{o}}-P_{\mathrm{c}}}{1-P_{\mathrm{c}}}$,

where $P_{\mathrm{o}}$ is the proportion of observed agreement and $P$ is the proportion of chance agreement.

$P_{\mathrm{o}}=\frac{(a+d)}{n}$
$P_{\mathrm{c}}=\frac{\left(\frac{F_{1} \times G_{1}}{n}\right)+\left(\frac{F_{2} \times G_{2}}{n}\right)}{n}$

Algorithms for AATSR AOD retrieval used to underestimate AOD over different regions in China include the ADV, ORAC, and SU algorithms. On this basis, the agreement between ground-based observation data and satellite retrievals is assessed based on the ADV and SU algorithms (Che et al., 2015). The main aim of this new KAPPA coefficient is to evaluate the comprehensive performance of these algorithms. Its function is to represent not only the degree of underestimation but also the level of agreement between different datasets.

\section{Validation results and analysis}

We collected different validation reference data of AERONET and CARSNET in 2007, 2008, and 2010. Only 14 ground-based observation sites are available in 2007, of which some are located close to each other. Most are located in different provinces; however, the total number of sites is small and the space distribution is not uniform. Therefore, the number of matches is relatively small for all of the algorithms. More AERONET and CARSNET data are available in 2008, with a total of 32 sites, made up of 8 AERONET sites and 24 CARSNET sites. There 
are 14 AERONET and CARSNET sites providing data for validation in 2010. The focus of this paper is to determine the differences between the ADV, ORAC, and SU L2 AOD products (see Table 4 and Fig. 1). Therefore, we calculated statistics and analysed the validation results separately by year (see Table 4 and Fig. 1).

\subsection{Validation results}

\subsubsection{The ADV algorithm}

For 2007, the RMSE is 0.095 and the RMB is 0.704 , which reflects the tendency of underestimation. This type of underestimation is more severe with increasing AOD. Low dispersion and slight underestimation make the KAPPA coefficient high (0.473), demonstrating that the ADV algorithm performs well in calculating the AOD over China in 2007. The ADV algorithm is appropriate for the retrieval of low AODs, especially for those less than 1.0; thus, the MSA for 2007 is 0.244 . For 2008, the lower RMB (0.621) suggests more severe underestimation, and higher relative mean bias (0.130) indicates lower accuracy. Similar to 2007, the MSA of the ADV is 0.211. Therefore, the KAPPA coefficient, which measures the overall performance, is 0.329 , lower than that of 2007. For 2010, ADV/AOD has the lowest RMSE (0.089) with the lowest accidental error of the 3 years. However, the KAPPA coefficient is 0.180 , also the lowest of the 3 years. The most obvious feature of the ADV algorithm is underestimation with the highest MSA being 0.250 in 2007 and the lowest being 0.173 in 2010. The ADV algorithm can retrieve low AOD values with high accuracy. This "ability" is systematic for either high AODs or low AODs. This also limits the range of application of the ADV algorithm, especially in calculating AODs in high-value ranges.

\subsubsection{The ORAC algorithm}

The ORAC algorithm performed well for 2007, achieving a KAPPA coefficient of 0.474 . However, the distribution of matches is dispersed, implying high RMSE (0.206). In terms of the degree of fitness, its performance is not effective. However, there is no obvious trend of underestimation or overestimation, and accidental errors influence the accuracy of the ORAC algorithm. The MSA of the ORAC is 0.324. ORAC has the most matches of the three algorithms. Differently from 2008, no obvious underestimation occurs in the results of 2007 and 2010. For 2008, the RMB is 0.829 , suggesting a slight underestimation trend. The applicability of ORAC is high, with MSA of 0.271 . The collocated pairs are relatively dispersed, influencing the RMSE. For 2010, the same dispersion of points in the scatter plot and low KAPPA coefficient are observed. Overall, the ORAC algorithm tends to retrieve AODs unstably for either high AODs or low AODs and with a slight underestimation in 2007. The results of 2008 and
2010 share common features, indicating that accidental error is larger than systematic error.

\subsubsection{The SU algorithm}

The SU algorithm performed well for all 3 years, achieving KAPPA coefficients of $0.409,0.484$, and 0.520 , respectively. The RMBs are $0.816,0.713$, and 0.720 for 2007,2008 , and 2010 , respectively, demonstrating the underestimation of the SU product. The applicability of SU is high, with an MSA of 0.293 for 2008 . The most obvious feature of the SU algorithm is its stability in retrieving AOD for different years or different regions (Fig. 4). The MSA ranges from 0.270 for 2010 to 0.330 for 2007 , and the KAPPA coefficient ranges from 0.520 to 0.409 , which suggests that the $\mathrm{SU}$ algorithm performed better at retrieving low AODs. The SU algorithm has the best performance in terms of AOD retrieval, as it has the highest KAPPA coefficient (0.520). Overall, the SU algorithm can be applied to retrieve AOD in different ranges with high precision. Factors influencing the performance of the SU algorithm include a small systematic error and even a smaller accidental error.

\subsection{Uncertainty analysis based on aerosol loading}

In the previous section, we validated all three AOD products over mainland China in 2007, 2008, and 2010, discovering that all three products tend to exhibit underestimation to some extent. For the purpose of ascertaining the causes of the underestimation, in this section, we focus on analysing the AOD uncertainties leading to differences between retrieved AODs and ground-based AODs in special conditions. Collocated pairs are divided into three groups according to aerosol loading, including light loading $(\tau<0.15)$, heavy loading ( $\tau>0,4)$, and moderate loading (Levy et al., 2010). It is obvious that the AOD bias increases with increasing AOD for all three products. These products have one feature in common, that is, the AOD bias tends to be negative, which indicates that the underestimation becomes more significant with increasing aerosol loading. The ADV and SU algorithms perform well in estimating AOD, i.e. with little underestimation (lower MBEs of -0.04 and -0.02 , respectively, as shown in Table 5), when aerosol loading is low (light loading) (Fig. 3).

Under complex conditions, the ORAC overestimates AOD in regions of light loading and moderate loading compared with AERONET and CARSNET, as shown in Fig. 3. ADV tends to underestimate AOD more severely, with $\mathrm{MBE}=-0.11$ in a moderate aerosol loading region. Similarly to ADV, the underestimation of SU in moderate aerosol loading becomes more severe, with $\mathrm{MBE}=-0.07$. ORAC performs the best in retrieving in a moderate aerosol loading regions without underestimation or overestimation, even though the bubbles are distributed discretely with an SD of 0.18 (see in Table 5). The performances of all three algo- 
Table 4. Main statistics of the validation results.

\begin{tabular}{llrrrrrrrr}
\hline & & $N$ & MSA & MAA & MBE & MAE & RMSE & RMB & KAPPA \\
\hline AATSR ADV & 2007 & 94 & 0.25 & 0.36 & -0.11 & 0.12 & 0.15 & 0.70 & 0.49 \\
& 2008 & 327 & 0.22 & 0.36 & -0.14 & 0.15 & 0.20 & 0.61 & 0.37 \\
& 2010 & 147 & 0.17 & 0.31 & -0.14 & 0.14 & 0.22 & 0.55 & 0.23 \\
& 3 years & 568 & 0.21 & 0.35 & -0.13 & 0.14 & 0.20 & 0.61 & 0.38 \\
\hline \multirow{2}{*}{ AATSR ORAC } & 2007 & 145 & 0.35 & 0.28 & 0.06 & 0.14 & 0.23 & 1.23 & 0.50 \\
& 2008 & 648 & 0.29 & 0.33 & -0.04 & 0.16 & 0.27 & 0.87 & 0.45 \\
& 2010 & 298 & 0.26 & 0.27 & -0.01 & 0.14 & 0.23 & 0.96 & 0.37 \\
& 3 years & 1091 & 0.29 & 0.31 & 0.02 & 0.15 & 0.25 & 0.93 & 0.44 \\
\hline AATSR & 2007 & 98 & 0.33 & 0.41 & -0.07 & 0.09 & 0.16 & 0.83 & 0.43 \\
SU & 2008 & 446 & 0.29 & 0.41 & -0.12 & 0.13 & 0.21 & 0.72 & 0.50 \\
& 2010 & 171 & 0.27 & 0.37 & -0.10 & 0.12 & 0.21 & 0.73 & 0.53 \\
& 3 years & 715 & 0.29 & 0.40 & -0.11 & 0.12 & 0.20 & 0.73 & 0.50 \\
\hline
\end{tabular}
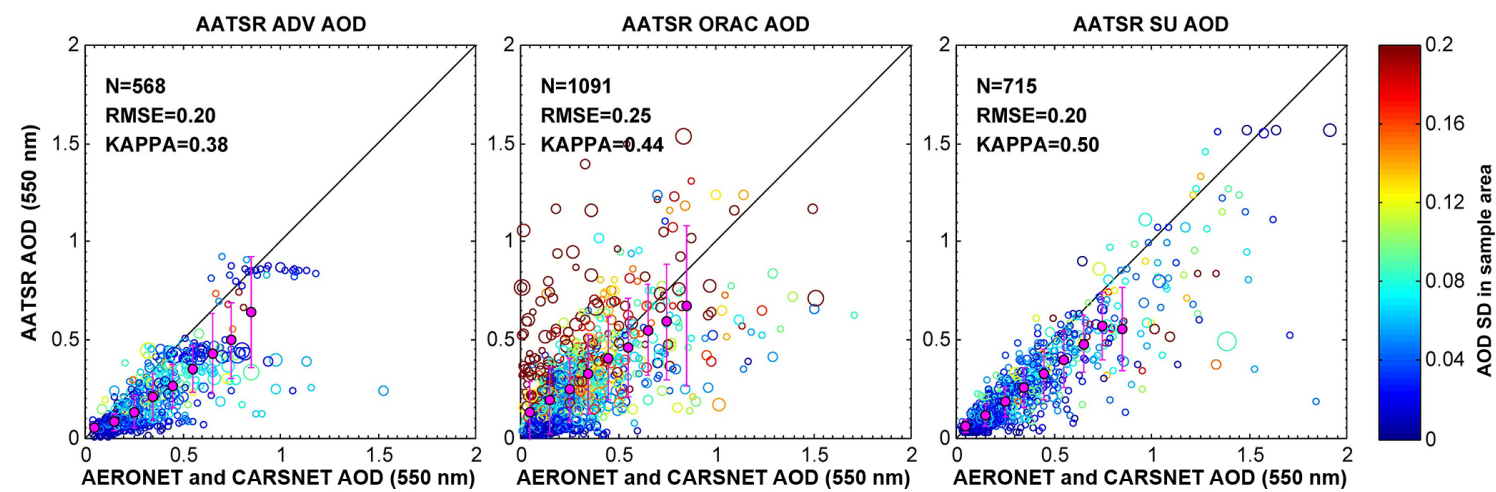

Figure 2. Scatter plots of AATSR ADV, ORAC, and SU L2 AOD products with ground-based data in China for the 3 years of 2007, 2008, and 2010. The black solid line represents the 1-1 line. The magenta points are means for specific ranges of AERONET and CARSNET AOD, and the magenta lines are the mean $\pm 2 \sigma$ of retrievals in a certain range. The areas and colours are determined by the means of uncertainty (MU) dataset in AATSR L2 products and the standard deviation of retrievals (Std_S) in a collocation frame of $50 \mathrm{~km} \times 50 \mathrm{~km}$, respectively.

rithms are at the same level, with close MBEs, SDs, and RMSEs in heavy aerosol loading regions.

The top and bottom borders of the box we draw represent the interval of $[-2 \sigma, 2 \sigma]$, which contains most of the data (approximately $95 \%$ ) for a given group. The data outside the box are "possible outliers" based on the largest error contained in each group. Those possible outliers have one feature in common in that the corresponding points in the bias scatter plot are far away from other points. Otherwise, the points below or above the box are different. If a point is above the box, which indicates that the satellite-retrieved AOD is larger than the ground-based observed AOD, this outlier tends to be caused by a residual cloud. The ground-based network measures AOD from only one point; however, the satelliteretrieved AODs in each collocated pair are an average of 25 pixels. Any one of these 25 pixels with a cloud residual will lead to an increased AOD in a collocated pair. Therefore, we conclude that the outliers above the box are possibly caused by cloud residual. From this point of view, there are 6, 6, and 2 bubbles above each box for the ADV product for light, moderate, and heavy aerosol loading, respectively. However, these bubbles are not possible outlier due to the means of uncertainty (MUs) and Std_Ss being relatively small, as shown in Fig. 3. Similarly, the bubbles from the SU product above each box are not possible outliers. For the ORAC product, most of the bubbles above each box are possible outliers due to larger Std_S $(>0.2)$. Most possible outliers are concentrated in light (13 bubbles) and moderate (14 bubbles) aerosol loading regions as shown in Table 5, influencing ORAC's performance in estimating AOD. The bubbles below the box are different from those above the box. Most of them are only below the boxes of moderate and heavy aerosol loading, indicating that all these algorithms have limitations of underestimation in estimating AOD in moderate and heavy aerosol loading regions, especially when the AOD loading increases.

We make these groups because aerosols exhibit different behaviours with different loading conditions. In general, the bias or uncertainty of satellite-retrieved AOD will increase with increasing AOD or aerosol loading. As discussed above, all of these algorithms underestimate AOD at different levels; 

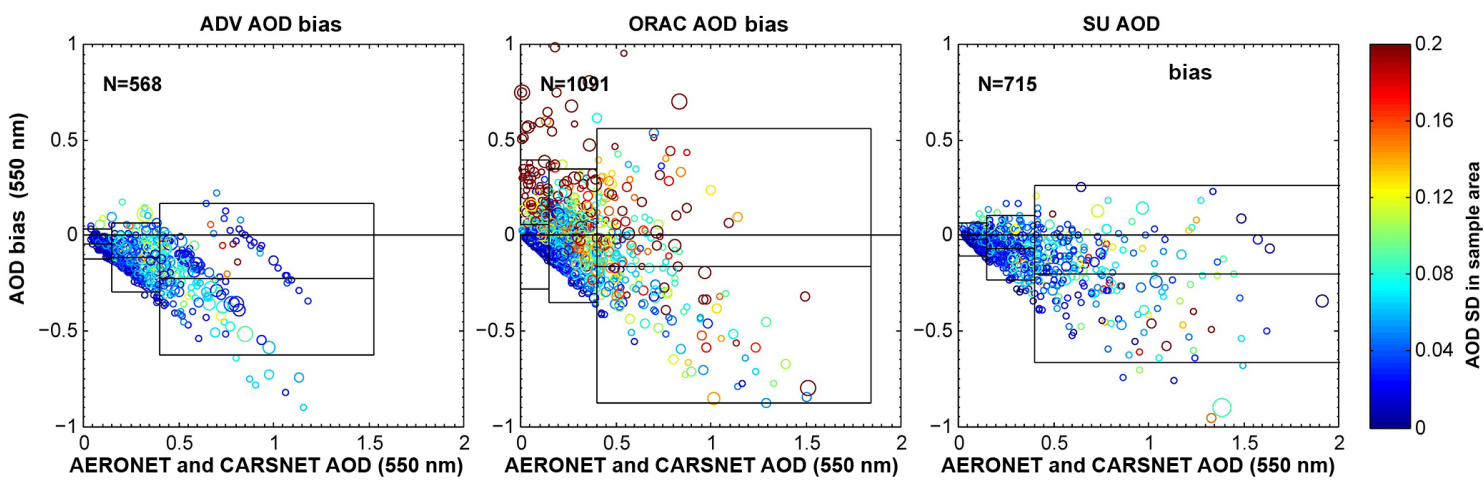

Figure 3. Scatter plot of AERONET and CARSNET AODs with ADV AOD bias or uncertainties in China in 2007, 2008, and 2010. The areas and colours of bubbles represent MU and Std_S sampling area of $50 \mathrm{~km} \times 50 \mathrm{~km}$, respectively. Colours represent different groups: blue denotes light loading, green denotes moderate loading, and red denotes heavy loading. Each group has one box, the bottom and top borders of which represent $\mathrm{MBE}+2 \sigma$ and $\mathrm{MBE}-2 \sigma$, respectively, containing $96 \%$ of scattered points of each group. The centre line of each box represents the $\mathrm{MBE}$ of each group.

similarly, it is worth noting that underestimation becomes more severe with increasing AOD or aerosol loading.

Additionally, we make a comparison of AOD bias, which is retrieval errors observed, with AOD uncertainty in AOD retrieval for each pixel the from AATSR L2 dataset. AOD retrieval error observed (AOD bias) and AOD uncertainty in retrieval are different as evaluating merits. The range of $\mathrm{SU}$ AOD uncertainty is from 0.025 to 0.3 , smaller than others, even in heavy aerosol loading regions. Most bubbles of the ADV product in Fig. 3. are from 0 to 0.4 of AOD uncertainty. The AOD bias and uncertainty are small in light aerosol loading and moderate for ADV and SU products, as shown in Fig. 4. For the ORAC product, there is no obvious regularity between AOD bias with AOD uncertainty in three aerosol loading regions, especially those bubbles with high Std_S.

\subsection{Uncertainty analysis of individual ground measurement sites}

For the purpose of further evaluating the different performances of these three algorithms in estimating AOD over mainland China, we validate these products on a site-by-site basis. It is significant to explore the roles of different factors in estimating AOD. There are several factors that may have impacts on AOD calculation, including land cover, aerosol type, and elevation. Therefore, we analyse different validation results of each site to study how these factors work (see Table 6).

\subsubsection{Intercomparison of algorithms site by site}

In this section, we select five representative AERONET and CARSNET sites with more than 30 successful matches in 2007, 2008, and 2010 to guarantee an appropriate statistical sample size. These selected sites are located in different regions where the land cover and climatic pattern are different and representative of mainland China. Two AERONET sites and three CARSNET sites were selected, including SACOL and Xianghe from AERONET, and Lin'an, Shangdianzi and Xilinhot from CARSNET. Most matches of the ADV and SU products collocated with ground-based data occurred in March to October in 2007, 2008 and 2010, as shown in Figs. 5 to 9 . The matches of the ORAC product were distributed in each month over most sites.

Lin' an is located at $30.3^{\circ} \mathrm{N}, 119.73^{\circ} \mathrm{E}$, northwest of Zhejiang province. A total of $80 \%$ of the $50 \mathrm{~km} \times 50 \mathrm{~km}$ surrounding area is covered by green vegetation, and the other $20 \%$ is covered with urban land. The ADV and ORAC algorithm underestimated AOD, with $\mathrm{MBE}=0.13$ and 0.12 in 2010, respectively (see Fig. 5). The SU performed well in Lin'an, with slight underestimation. The underestimation of the ADV algorithm is more severe than that of SU and ORAC. Although the ORAC algorithm has the most matches in Lin'an, its performance was unstable, which means that the level of underestimation was different in different years.

SACOL is situated along the southern bank of the Yellow River in Lanzhou city, Gansu province. Lanzhou city has a temperate continental climate with four clearly distinct seasons. The dominant land cover is grassland, covering approximately $95 \%$ of the spatial extent of the $50 \mathrm{~km} \times 50 \mathrm{~km}$ area from the MODIS MCD12C1 land cover data. A total of 30\% of the surface consists of arid and semi-arid areas, which can be a source of dust aerosols. SU performs well in retrieving AOD over SACOL, with a low RMSE (0.072). The accidental error in the retrievals using the ORAC algorithm is obvious, leading to a high RMSE (0.170). However, as discussed above, the ADV algorithm severely underestimated AOD in SACOL. The ADV algorithm tended to severely underestimate the AOD of different ranges, except for a small number of high-quality matches. The matches of the SU product are of high quality for the 3 years. The ORAC has collocated matches in January, February, November, and December (winter time), unlike the ADV and SU products. How- 
Table 5. Statistics of comparison between AOD bias and ground-based measurements. Proportion is the ratio of the number of bubbles falling in each box to the total number. RMSE1 and RMSE2 are RMSEs of AOD bias with ground-based measurement and AOD uncertainty, respectively.

\begin{tabular}{llrrrrrrrr}
\hline \multirow{2}{*}{ Algorithm } & Class & $\mathrm{N}$ & Proportion & MBE & RMSE_ & SD & Above & Below & RMSE2 \\
\hline AATSR & Total & 568 & $100.0 \%$ & -0.13 & 0.20 & 0.15 & 14 & 14 & 0.27 \\
ADV & Light & 126 & $22.2 \%$ & -0.04 & 0.03 & 0.04 & 6 & 0 & 0.07 \\
& Moderate & 259 & $45.6 \%$ & -0.11 & 0.10 & 0.09 & 6 & 6 & 0.22 \\
& Heavy & 183 & $32.2 \%$ & -0.23 & 0.17 & 0.20 & 2 & 8 & 0.35 \\
\hline AATSR & Total & 1091 & $100.0 \%$ & 0.02 & 0.25 & 0.25 & 32 & 8 & 3.65 \\
ORAC & Light & 347 & $31.8 \%$ & 0.059 & 0.10 & 0.17 & 13 & 0 & 0.13 \\
& Moderate & 468 & $42.9 \%$ & 0 & 0.11 & 0.18 & 14 & 2 & 0.28 \\
& Heavy & 276 & $25.3 \%$ & -0.16 & 0.20 & 0.36 & 5 & 6 & 5.56 \\
\hline AATSR & Total & 715 & $100.0 \%$ & -0.11 & 0.20 & 0.17 & 8 & 22 & 0.24 \\
SU & Light & 147 & $20.6 \%$ & -0.02 & 0.02 & 0.04 & 3 & 1 & 0.08 \\
& Moderate & 306 & $42.8 \%$ & -0.07 & 0.07 & 0.08 & 5 & 12 & 0.16 \\
& Heavy & 262 & $36.6 \%$ & -0.2 & 0.19 & 0.23 & 0 & 9 & 0.34
\end{tabular}
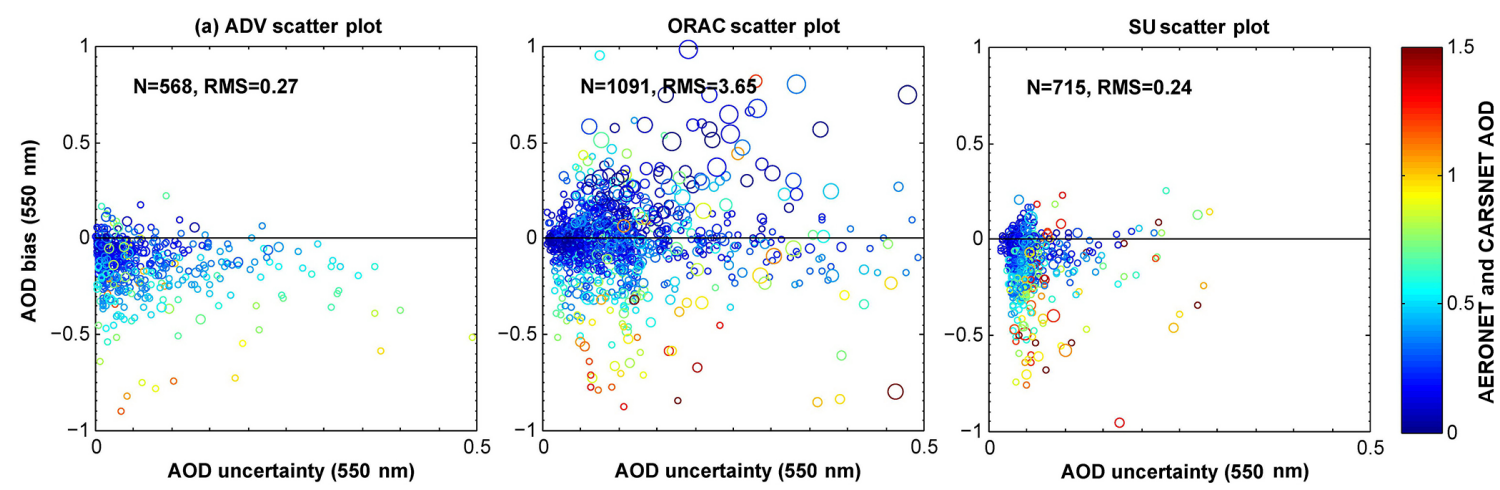

Figure 4. Scatter plots of ADV, ORAC, and SU AOD uncertainty with AOD bias over China for the 3 years of 2007, 2008, and 2010. The area and colours of bubbles represent Std_S and AOD, respectively.

ever, the accuracy of ORAC in winter is highly uncertain, as shown in Fig. 6.

Shangdianzi is situated at $40.15^{\circ} \mathrm{N}, 94.68^{\circ} \mathrm{E}$, with complex land cover of approximately $45 \%$ cropland, $30 \%$ mixed forest, $18 \%$ closed shrubland, $5 \%$ grassland, $1 \%$ water, and $1 \%$ evergreen needle leaf forest. The SU algorithm has high precision in AOD calculation over this site from March to October, when most of the land cover is green. The ADV algorithm also performs well in calculating AOD over these three sites, with a slight underestimation. The performance of the ORAC algorithm in Shangdianzi is unstable, with strong agreement with ground-based data from March to October and severe underestimation in winter, as shown in Fig. 7.

Xianghe is located to the southeast of Beijing and has the same climatic conditions as Beijing. Approximately $98 \%$ of the surface is covered with urban land according to the MCD12C1 data of a $50 \mathrm{~km} \times 50 \mathrm{~km}$ area. The performances of these three algorithms are at the same high-quality level (see Fig. 8). However, the ADV algorithm still underesti- mated AOD at a level of $\mathrm{MBE}=0.12$ in 2007 and 0.10 in 2008.

Xilinhot is situated at $43.95^{\circ} \mathrm{N}, 116.07^{\circ} \mathrm{E}$, at the centre of the Xilinguole grassland. The main land cover is grassland $(100 \%)$ based on the MODIS MCD12C1 data, with a spatial extent of $50 \mathrm{~km} \times 50 \mathrm{~km}$. The surface and climate features of Xilinhot are similar to those of SACOL, and the performance of the SU algorithm at these two sites is the same, i.e. both with low RMSE (see Fig. 9). The ADV algorithm slightly underestimated AOD, with an MBE of 0.10-0.13. The ORAC AOD showed weak agreement with the Xilinhot data, mainly because possible outliers exist in March to June 2008 and March 2010.

To guarantee statistical reliability, there must be more than 30 collocated pairs at one site. The determination of the surface cover at each site is based on the proportion (>80\% for one land type) of each land cover type from the MCD12C1 data at a spatial extent of $50 \mathrm{~km} \times 50 \mathrm{~km}$. If no land cover type accounts for a proportion larger than $80 \%$ at a given site, it will be identified as mixed; then, we select two or 
Table 6. Statistics of validation results of different products over different sites.

\begin{tabular}{llrlllllll}
\hline Site & Algorithm & $\mathrm{N}$ & MSA & MAA & MBE & MAE & RMSE & RMB & KAPPA \\
\hline Lin'an & ADV & 33 & 0.346 & 0.462 & -0.116 & 0.122 & 0.088 & 0.748 & 0.341 \\
& ORAC & 48 & 0.426 & 0.470 & -0.044 & 0.131 & 0.144 & 0.906 & 0.668 \\
& SU & 40 & 0.430 & 0.484 & -0.054 & 0.082 & 0.093 & 0.889 & 0.650 \\
\hline \multirow{2}{*}{ SACOL } & ADV & 46 & 0.156 & 0.285 & -0.129 & 0.132 & 0.068 & 0.547 & 0.283 \\
& ORAC & 74 & 0.286 & 0.314 & -0.028 & 0.102 & 0.170 & 0.910 & 0.595 \\
& SU & 49 & 0.265 & 0.291 & -0.027 & 0.062 & 0.072 & 0.908 & 0.878 \\
\hline \multirow{2}{*}{ Shangdianzi } & ADV & 52 & 0.172 & 0.297 & -0.125 & 0.131 & 0.087 & 0.578 & 0.339 \\
& ORAC & 66 & 0.267 & 0.304 & -0.037 & 0.107 & 0.134 & 0.879 & 0.407 \\
& SU & 46 & 0.285 & 0.402 & -0.117 & 0.128 & 0.101 & 0.710 & 0.457 \\
\hline Xianghe & ADV & 33 & 0.184 & 0.284 & -0.100 & 0.102 & 0.070 & 0.649 & 0.169 \\
& ORAC & 34 & 0.227 & 0.240 & -0.013 & 0.091 & 0.096 & 0.946 & 0.577 \\
& SU & 36 & 0.368 & 0.392 & -0.024 & 0.058 & 0.077 & 0.939 & 0.444 \\
\hline Xilinhot & ADV & 49 & 0.082 & 0.198 & -0.116 & 0.117 & 0.046 & 0.414 & 0.148 \\
& ORAC & 110 & 0.190 & 0.182 & 0.008 & 0.109 & 0.166 & 1.043 & 0.389 \\
& SU & 61 & 0.140 & 0.220 & -0.081 & 0.085 & 0.063 & 0.634 & 0.444 \\
\hline
\end{tabular}
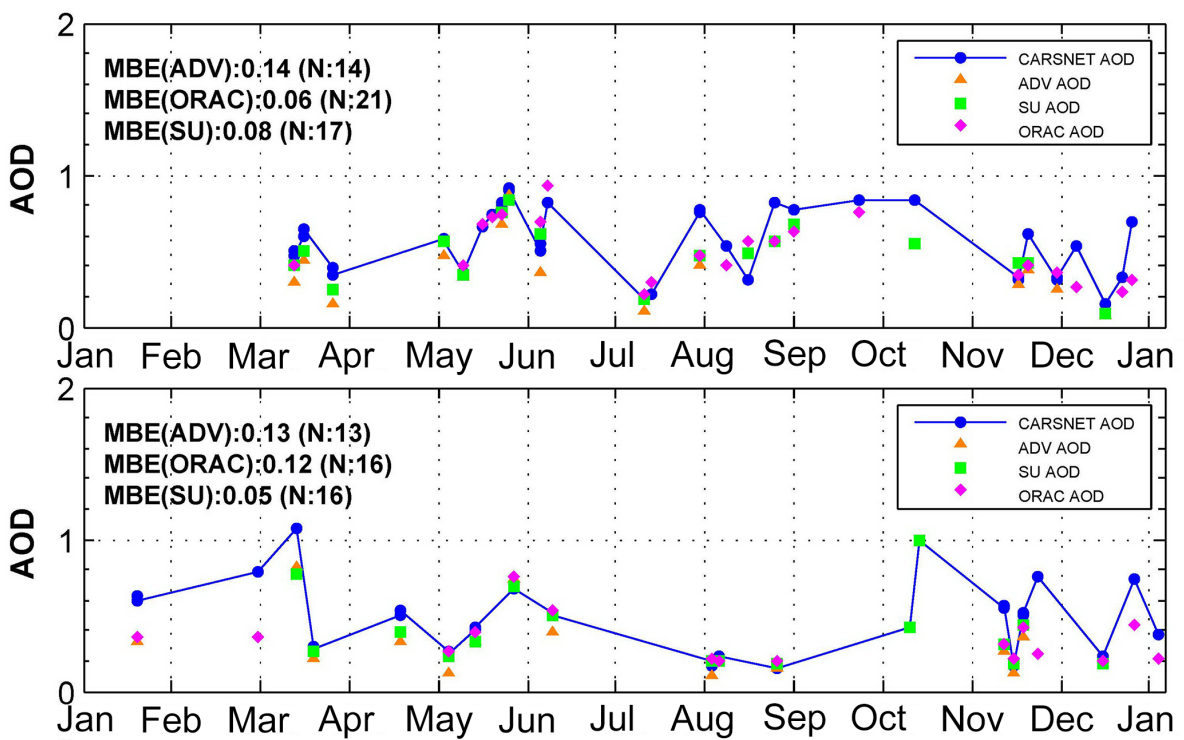

Figure 5. Time series comparison of AATSR AOD with CARSNET AOD at Lin' an in 2008 and 2010.

more (sum $>80 \%$ ) land types with the largest proportions as the main land cover. As the data volume is too low to infer the year-to-year variability of performance at these sites, the analysis gives some useful information, but it is important not to overinterpret results from a small selection of data points.

\subsubsection{Analysis of algorithm performances in western China}

Because sufficient ground-based data in western China are lacking for the AERONET measurements, only data from CARSNET sites are used in 2008. We selected six
CARSNET sites located in western China in which there are more than 25 matches.

Urumchi, situated at $43.78^{\circ} \mathrm{N}, 87.62^{\circ} \mathrm{E}$, serves as the provincial capital of Xinjiang Uyghur Autonomous Region and is the most remote city in China in terms of distance to any sea. The dominant land cover at the spatial extent of $50 \mathrm{~km} \times 50 \mathrm{~km}$ is grassland, which accounts for approximately $85 \%$. The ADV, ORAC, and SU algorithms all severely underestimated $\mathrm{AOD}$, with $\mathrm{MBE}=0.22,0.12$, and 0.17 , respectively. The MBE is lowest mainly because of the outlier in April, which decreases the MBE (see Fig. 10). 

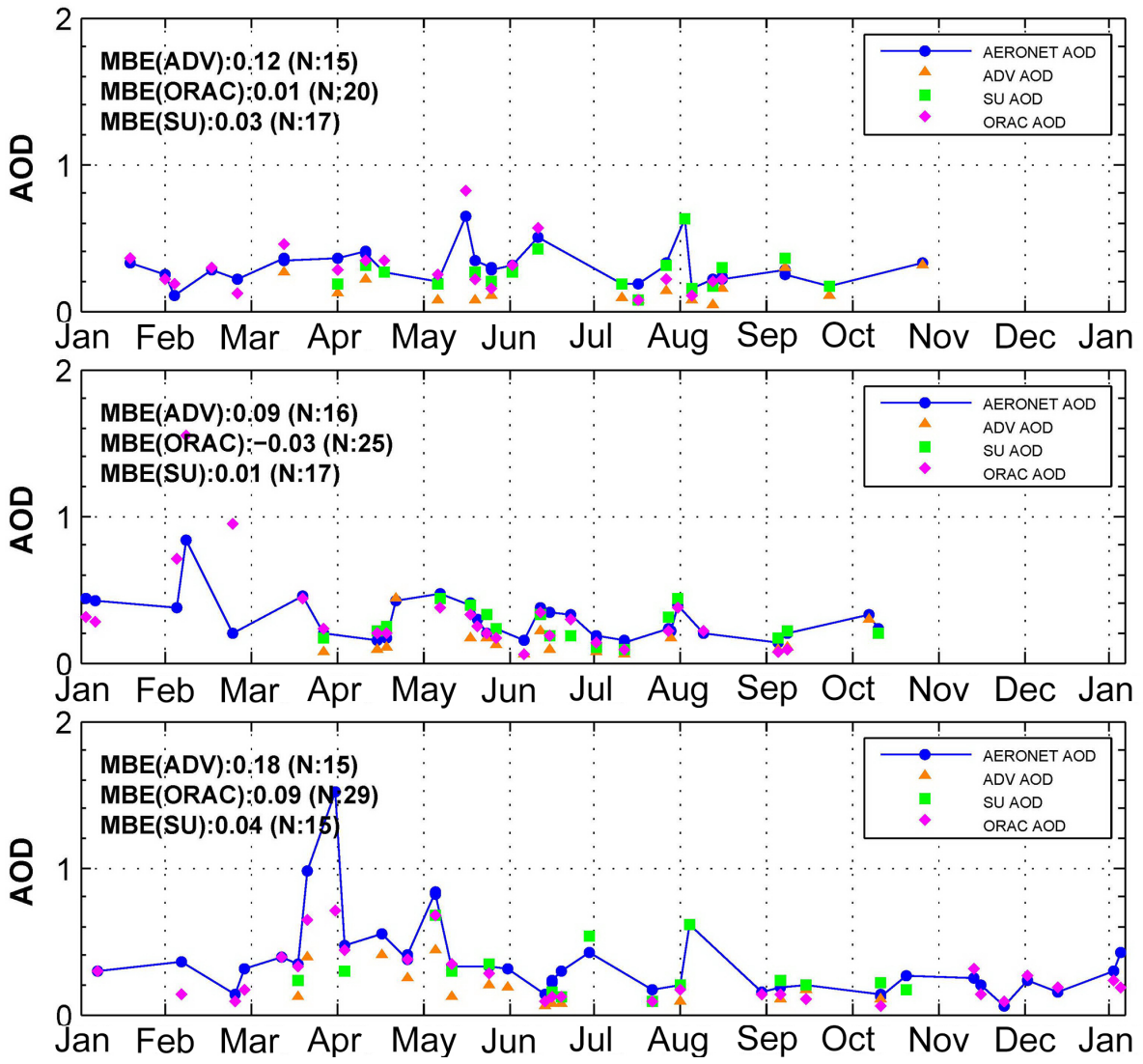

Figure 6. Time series comparison of AATSR AOD with AERONET AOD at SACOL in 2007, 2008, and 2010.

Ejina is situated at $41.95^{\circ} \mathrm{N}, 101.07^{\circ} \mathrm{E}$, and its main land cover is barren ground $(84 \%)$. The performances of ORAC and $\mathrm{SU}$ are at the same high-quality level, with MBEs of 0.02 and 0.09 , respectively. Another reason why we chose this site is that there are no matches of ADV products successfully collocated with ground-based data. Based on Fig. 11, the ORAC algorithm has strong applicability in Ejina and high accuracy in retrieving AOD. The SU algorithm also performed well. This demonstrates that another limitation of the ADV algorithm is its applicability in calculating AOD in China. Dunhuang is situated at $40.15^{\circ} \mathrm{N}, 94.68^{\circ} \mathrm{E}$ and is surrounded by barren ground $(85 \%)$. The same situation is true for Ejina, which causes a slight underestimation at each point but high R and low RMSE for the ORAC algorithm (Fig. 12). The performance of the SU algorithm was not as good as that of the ORAC because of its underestimation with $\mathrm{MBE}=0.10$. The limits of underestimation and applicability of the ADV were more obvious at this site, as it only had six matches and showed severe underestimation with $\mathrm{MBE}=0.17$. Tazhong is situated at $39^{\circ} \mathrm{N}$, $83.67^{\circ} \mathrm{E}$ and is surrounded by barren or sparsely vegetated surface. Almost all land cover is barren ground according to the MODIS MCD12C1 data. Similar to the former two sites, the ADV product did not have any successful matches at this
Table 7. DR distribution of specific sites.

\begin{tabular}{lrrrrr}
\hline Site & $\mathrm{DR}<1$ & $1<\mathrm{DR}<3$ & $3<\mathrm{DR}<5$ & $5<\mathrm{DR}$ & Total \\
\hline Urumchi & 47 & 40 & 2 & 1 & 90 \\
Ejina & 51 & 43 & 1 & 1 & 96 \\
Tazhong & 63 & 17 & 5 & 3 & 88 \\
Dunhuang & 57 & 31 & 1 & 2 & 91
\end{tabular}

site (Fig. 13). Both the ORAC and SU algorithms exhibited severe underestimation of retrievals, with $\mathrm{MBE}=0.17$ and 0.20 , respectively. The outliers of the ORAC product in February are much higher than the observation data, causing the lower MBE.

The prevailing climatic pattern in western China is a temperate continental climate with four distinct seasons and less precipitation in winter and spring. In conclusion, compared to eastern China, the applicability of the ADV algorithm is not strong, and the underestimation is more severe. In the four selected sites in western China, the performance of the ORAC algorithm is best, even though severe underestimation occurs at some sites. The accuracy of the SU algorithm is not as high as the ORAC product, with more severe underestimation and lower applicability. 

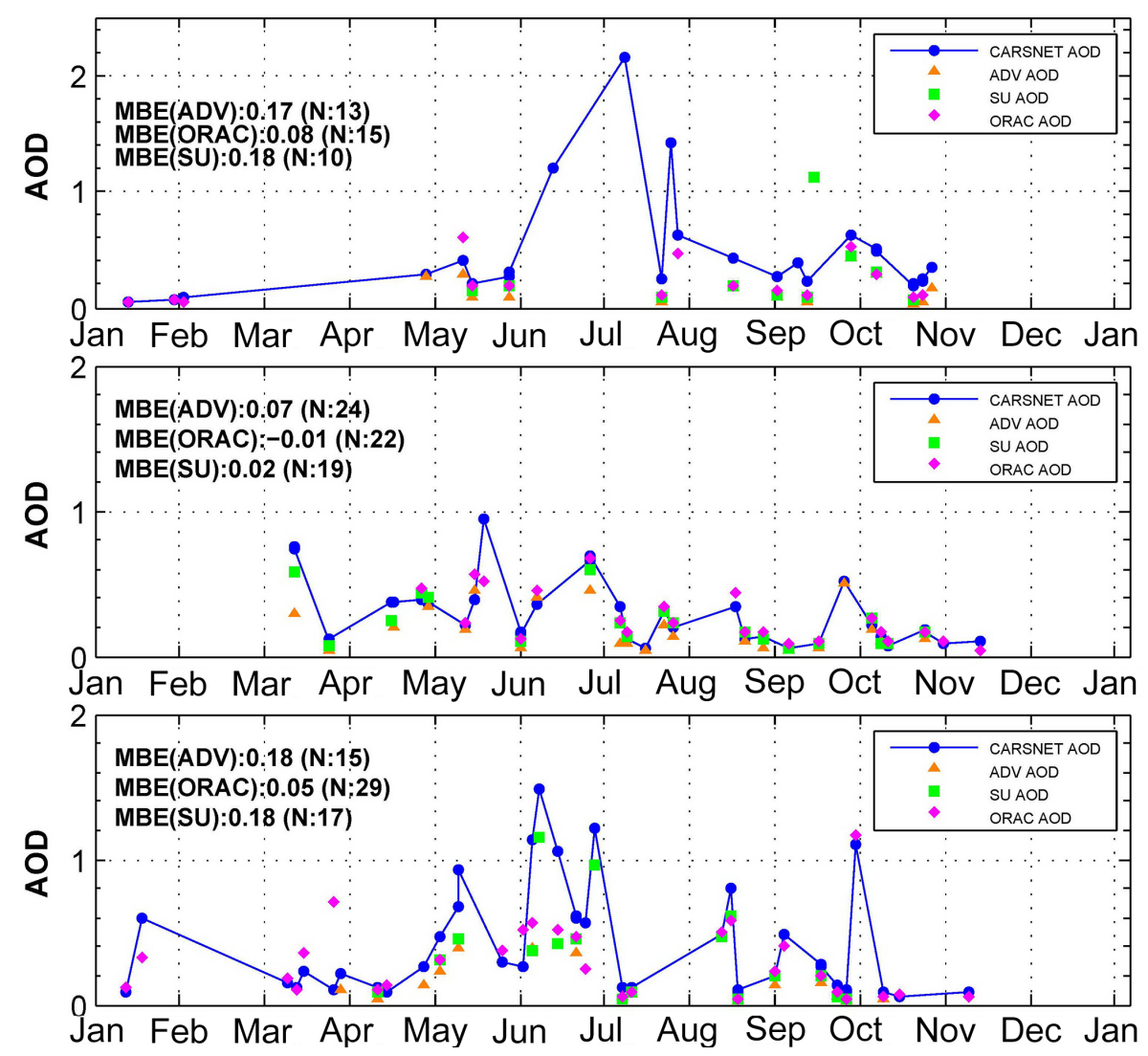

Figure 7. Time series comparison of AATSR AOD with CARSNET AOD at Shangdianzi in 2007, 2008, and 2010.

Table 8. Seasonal distribution of validation results of three algorithms.

\begin{tabular}{llrrrrrrrr}
\hline & & $\mathrm{N}$ & MSA & MAA & MBE & MAE & RMSE & RMB & KAPPA \\
\hline AATSR & Spring & 186 & 0.26 & 0.41 & -0.16 & 0.16 & 0.23 & 0.62 & 0.4 \\
ADV & Summer & 164 & 0.16 & 0.29 & -0.13 & 0.14 & 0.19 & 0.54 & 0.26 \\
& Autumn & 190 & 0.2 & 0.32 & -0.12 & 0.13 & 0.17 & 0.62 & 0.36 \\
AATSR & Spring & 294 & 0.35 & 0.37 & -0.02 & 0.18 & 0.3 & 0.95 & 0.5 \\
ORAC & Summer & 296 & 0.28 & 0.35 & -0.07 & 0.17 & 0.26 & 0.79 & 0.4 \\
& Autumn & 265 & 0.23 & 0.22 & 0.01 & 0.1 & 0.16 & 1.04 & 0.43 \\
& Winter & 230 & 0.29 & 0.28 & 0.01 & 0.15 & 0.25 & 1.03 & 0.38 \\
AATSR & Spring & 222 & 0.3 & 0.42 & -0.12 & 0.14 & 0.24 & 0.72 & 0.53 \\
SU & Summer & 241 & 0.32 & 0.43 & -0.11 & 0.13 & 0.2 & 0.74 & 0.49 \\
& Autumn & 237 & 0.26 & 0.35 & -0.09 & 0.11 & 0.16 & 0.74 & 0.49 \\
\hline
\end{tabular}

\subsubsection{Intercomparison}

In conclusion, the SU algorithm performs well in calculating AOD over different land covers from March to October. Slight underestimation occurs over barren ground or sparse vegetation at different times, and there are no obvious features in terms of precision in the time series over grasslands. For complex land surfaces where the dominant land cover is vegetation, the SU algorithm is extremely effective in estimating AOD. In the last section, we draw the conclusion that the SU algorithm underestimates AOD over mainland China in 2008 probably because the dominant land cover in western China is barren or sparse vegetation, over which the SU algorithm underestimates AOD more severely.

The ADV algorithm underestimates AOD at most of the selected sites. We categorize these sites as four classes according to the MBEs of different sites: Class $1(\mathrm{MBE}<0.1)$, Class $2(0.2>\mathrm{MBE}>0.1)$, Class $3(0.3>\mathrm{MBE}>0.2)$, and Class 4 (MBE $>0.3)$. The ADV algorithm underestimates AOD over all selected sites, leading to all selected MBEs 

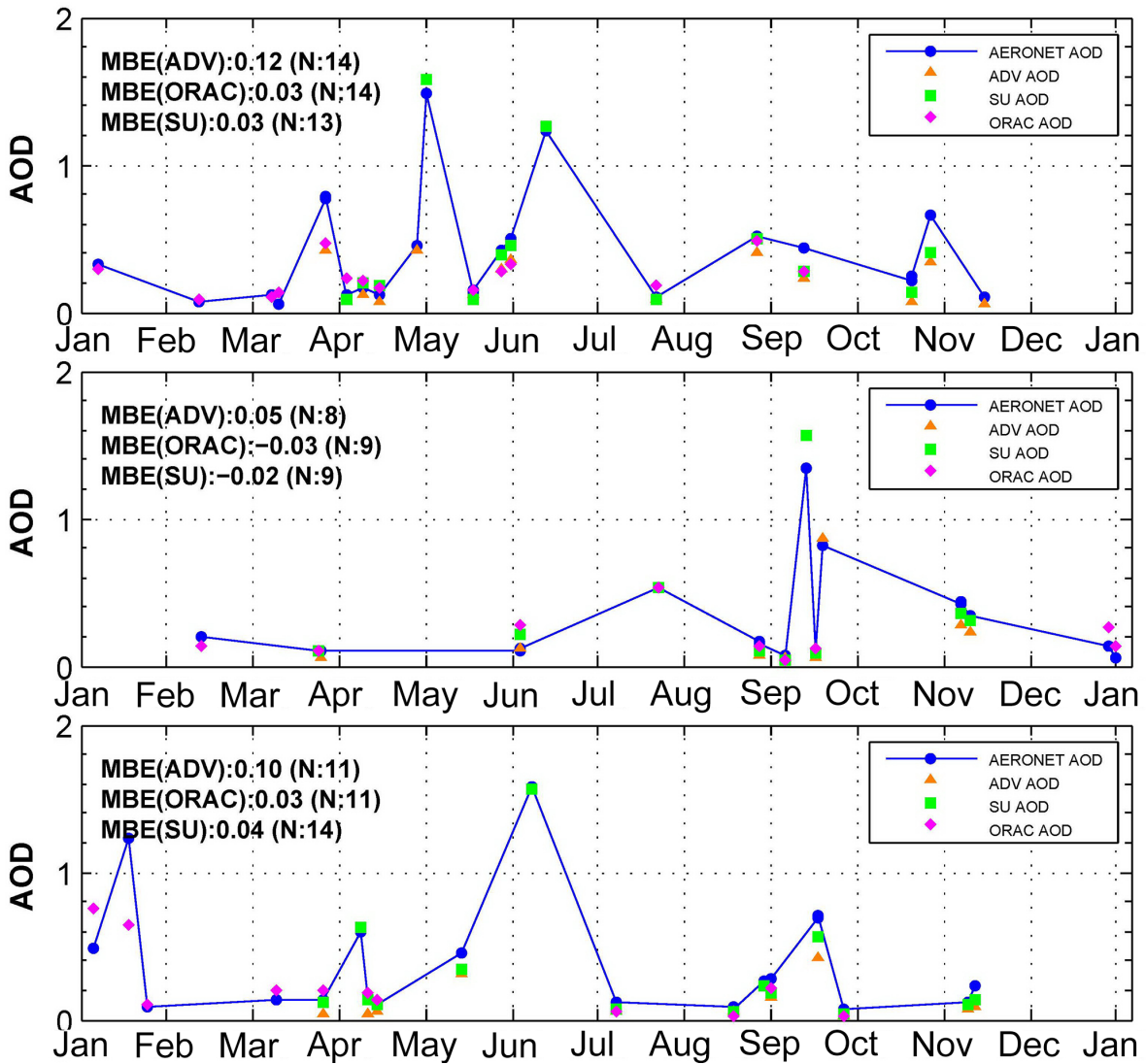

Figure 8. Time series comparison of AATSR AOD with AERONET AOD at Xianghe in 2007, 2008, and 2010.
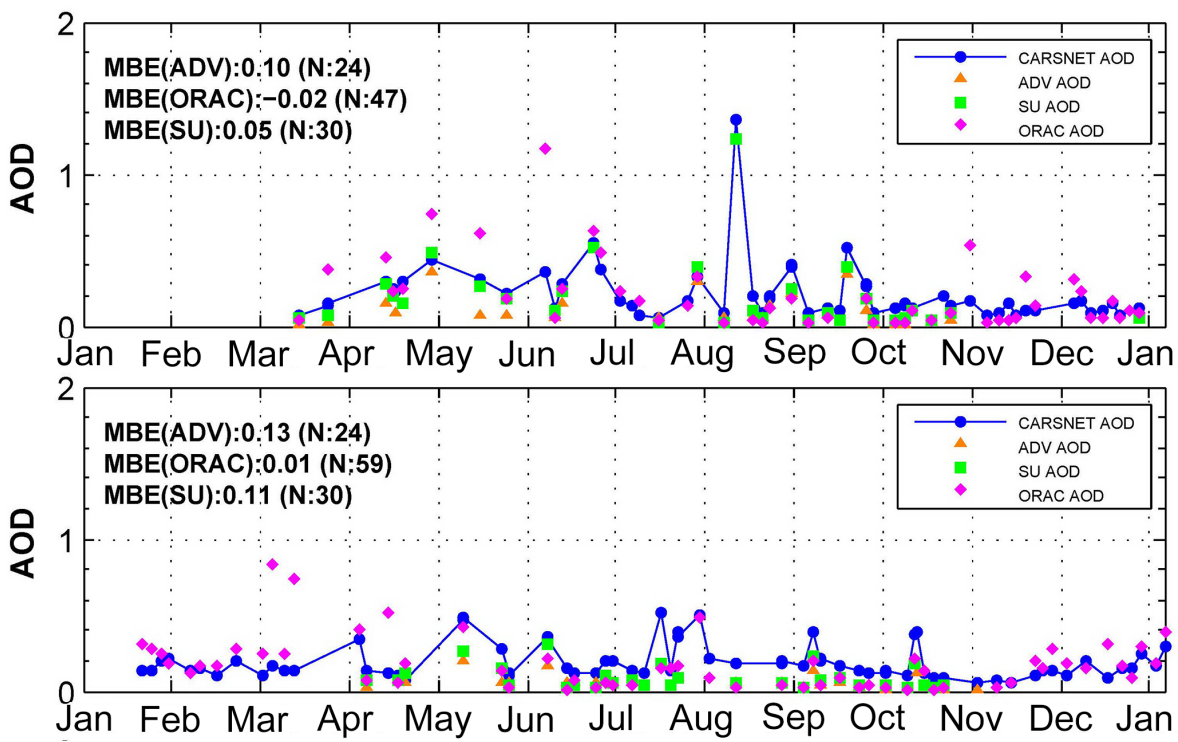

Figure 9. Comparison of SU AOD with CARSNET AOD at Xilinhot in 2008 and 2010.

being larger than 0 . We make such categories for the purpose of assessing the contribution of different surfaces to AOD estimation. Only Xianghe of 2008 belongs to Class 1, and Lin'an, Shangdianzi, and SACOL are classified as Class 2.
Only Urumchi is in Class 3. Note that even though Lanzhou and Datong were not selected due their location, they should be classified as Class 4 . 


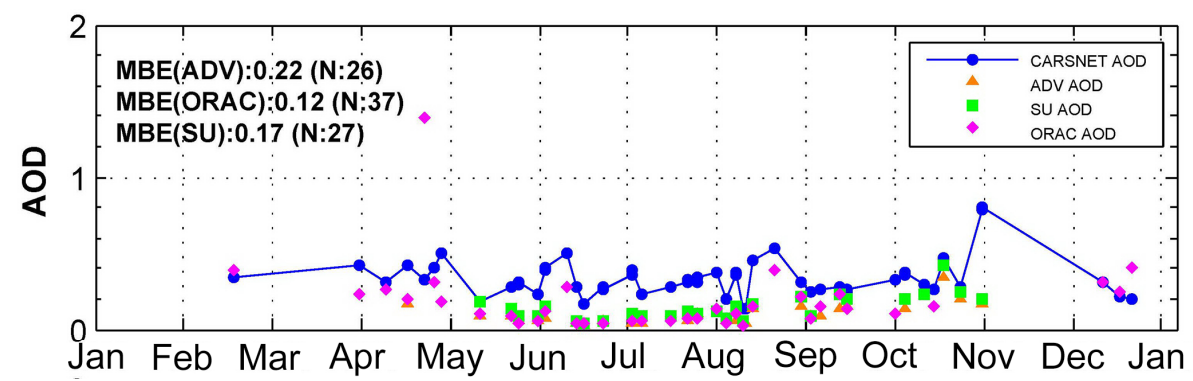

Figure 10. Time series comparison of AATSR AOD with CARSNET AOD at Urumchi in 2008.

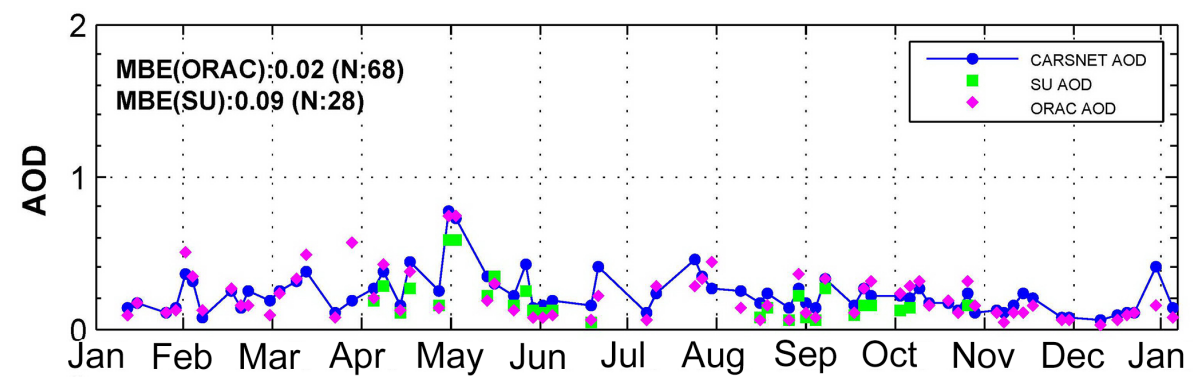

Figure 11. Time series comparison of AATSR AOD with CARSNET AOD at Ejina in 2008.

Overall, the ADV algorithm underestimates AODs at all sites but at different levels, as demonstrated by the above categories. Serious underestimation occurs over the sites in Class 3 and Class 4 in western China, where the dominant land cover is a mixing of urban area and a large portion of grasslands. For the sites in Class 2, differences exist between Beijing and SACOL. SACOL is similar to the sites in Class 3 and Class 4 , the main land cover of which is grassland. Over the sites in Class 1, the algorithm performs well with high $\mathrm{R}$ and low MBE, but there are no common features in terms of surface conditions.

The ORAC product collocates most pairs of all of these products. Most collocated pairs of the SU product and ADV product occur in March to October, but the collocated pairs of the ORAC product occur during each month over some sites in 2008. Because more matches suggest greater errors for the determination of the outlier contribution to the overall performance of the ORAC algorithm, we introduce the ratio of the individual difference to average the differences for each site:

$\mathrm{DR}=\frac{\left|\tau_{\text {aero }, i}-\tau_{\text {sate }, i}\right|}{\left(\sum_{i=1}^{n}\left|\tau_{\text {aero }, i}-\tau_{\text {Sate }, i}\right|\right)} / n$,

where $\mathrm{DR}<1$ indicates a "relatively good" match, $3>\mathrm{DR}>1$ indicates a "relatively poor" match, and DR $>3$ is an outlier (see Table 7).

There are no obvious possible outliers in Ejina shown in Fig. 11. Most of the DRs are in the range of 0 to 3, only two DRs are larger than 3, and the maximum (overestimation) is 5.112. The retrieved AOD in March is a possible outlier be- cause it is overestimated, whereas most are underestimated. Another two sites dominated by barren or sparsely vegetated land cover are Dunhuang (approximately $85 \%$ ) and Tazhong $(100 \%)$. The conditions in Tazhong are complex, and there is no obvious relationship between the CARSNET data and the ORAC AODs. Most of the DRs are less than 3, and a total of eight DRs are larger than 3. The DR in February is an outlier because the varying tendencies are different between the ORAC product and the ground-based data, indicative of overestimation.

The ORAC product has the largest coverage, at the expense of accuracy, especially in the presence of outliers, and only the ORAC product has collocated validation pairs over some sites during each month in all 3 years. The ORAC algorithm underestimates AODs over Ejina, Tazhong, and Dunhuang, but the possible outliers reduce the differences between the CARSNET data and the ORAC product. Xilinhot, Urumchi, and SACOL share the same main land cover of grassland. The problem is that the underestimations over these sites are not at the same level.

It is worth noting that the ORAC algorithm has the ability to calculate high AOD; however, most of the AODs have DRs larger than 3, indicating that the estimation of high AOD is unstable and has large error, reducing the overall precision.

\subsection{Seasonal characteristics of three algorithms}

Mainland China, covering about $60^{\circ}$ of longitude and $30^{\circ}$ of latitude, is dominated by a monsoon-driven climate. In such a vast territory, there are big differences in climate patterns 


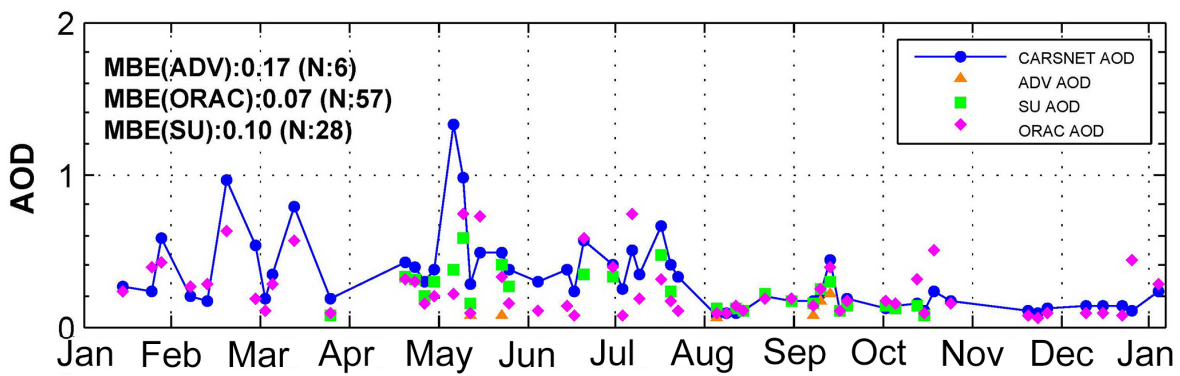

Figure 12. Time series comparison of AATSR AOD with CARSNET AOD at Dunhuang in 2008.

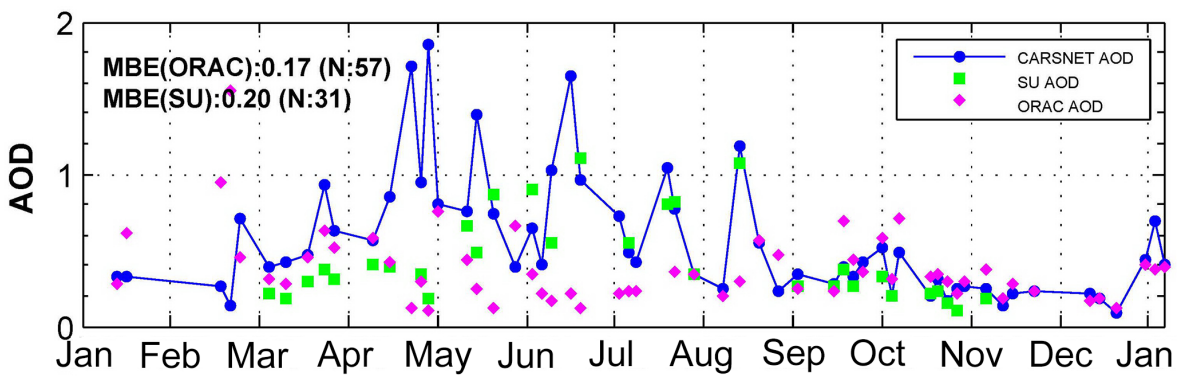

Figure 13. Time series comparison of AATSR AOD with CARSNET AOD over the site of Tazhong in 2008.

between western and eastern China. The main climate type in eastern and eastern coastal China is a monsoon climate. For western China far from the ocean, the climate type is a hybrid of a monsoon and continental climate. In dry seasons (winter, first half of spring, and last half of autumn), poor vegetation coverage, loose surface, and winds in most northern China regions turn coarse particles (sea salt and desert dust) into aerosol. Fine particles from coal combustion in winter and soot from straw burning in autumn are also an important source of aerosol. In rainy seasons (mainly in summer), high vegetation blocks dust being blown as aerosol and reduces surface reflectance in the visible wavelength. Table 8 shows the seasonal distribution of the validation results of the three algorithms. For mainland China, which is located in the Northern Hemisphere from $20-55^{\circ} \mathrm{N}$, the spring time starts on about March to May, the summer time starts in about June to August, the autumn time starts in about September to November, and the winter time is from about December to February of the next year.

Low MUs at $550 \mathrm{~nm}$ means that these retrievals are of high quality in Fig. 2. Most Std_S are below 0.08, indicating high uniformity of ADV products (see Fig. 2). Most collocated pairs of ADV AODs are concentrated below the 1-1 line, and the RMB is 0.61 , showing a tendency to underestimate. This kind of underestimation has an impact on ADV algorithm performances; for example, the RMSE is 0.19 in summer time, otherwise, the corresponding RMB is 0.54 , which makes the KAPPA coefficient the smallest $(0.26)$ of all seasons. The MBEs are from -0.12 in autumn to -0.16 in spring in Table 8, which means that the ADV algorithm tends to underestimate AOD in all seasons (except winter) over mainland China (See Fig. 13). For the monsoon climate, the main aerosol types in many parts of China are influenced by coarse particles (dust from western China and sea salt from eastern coastal China) in spring time. The performance in calculating aerosol properties of a mixture of coarse particles is best in spring time, with the highest KAPPA coefficient, even though there are some samples with high MUs and the RMSE is 0.23 .

The matches of the ORAC product collocated with reference data are distributed discretely at two sides of the 1-1 line in Fig. 2. The best performance, with a high KAPPA coefficient of 0.5 , is in spring with no underestimation, even though the RMSE is high (about 0.30). The KAPPA coefficient in the autumn time is lower than in the spring time, even though most evaluation metrics are better in the autumn. Note that only the ORAC product of these three products collocated enough matches (more than 30 ) with reference data in the winter time. The performance of ORAC in winter is between that in spring and autumn without obvious underestimation or overestimation. The limitation of the ORAC algorithm is the stability in retrieving aerosol properties, as shown in Fig. 14: the magenta mean $\pm 2 \sigma$ lines for each season in each range are longer than those for the other two products.

The SU algorithm has better performances in 3 years, getting KAPPA coefficients of 0.50 . Most retrievals in matches are of high quality collocated with reference data and most Std_S are lower than 0.08; i.e. the sample quality is high and this coincides with an assumption of aerosol property uni- 

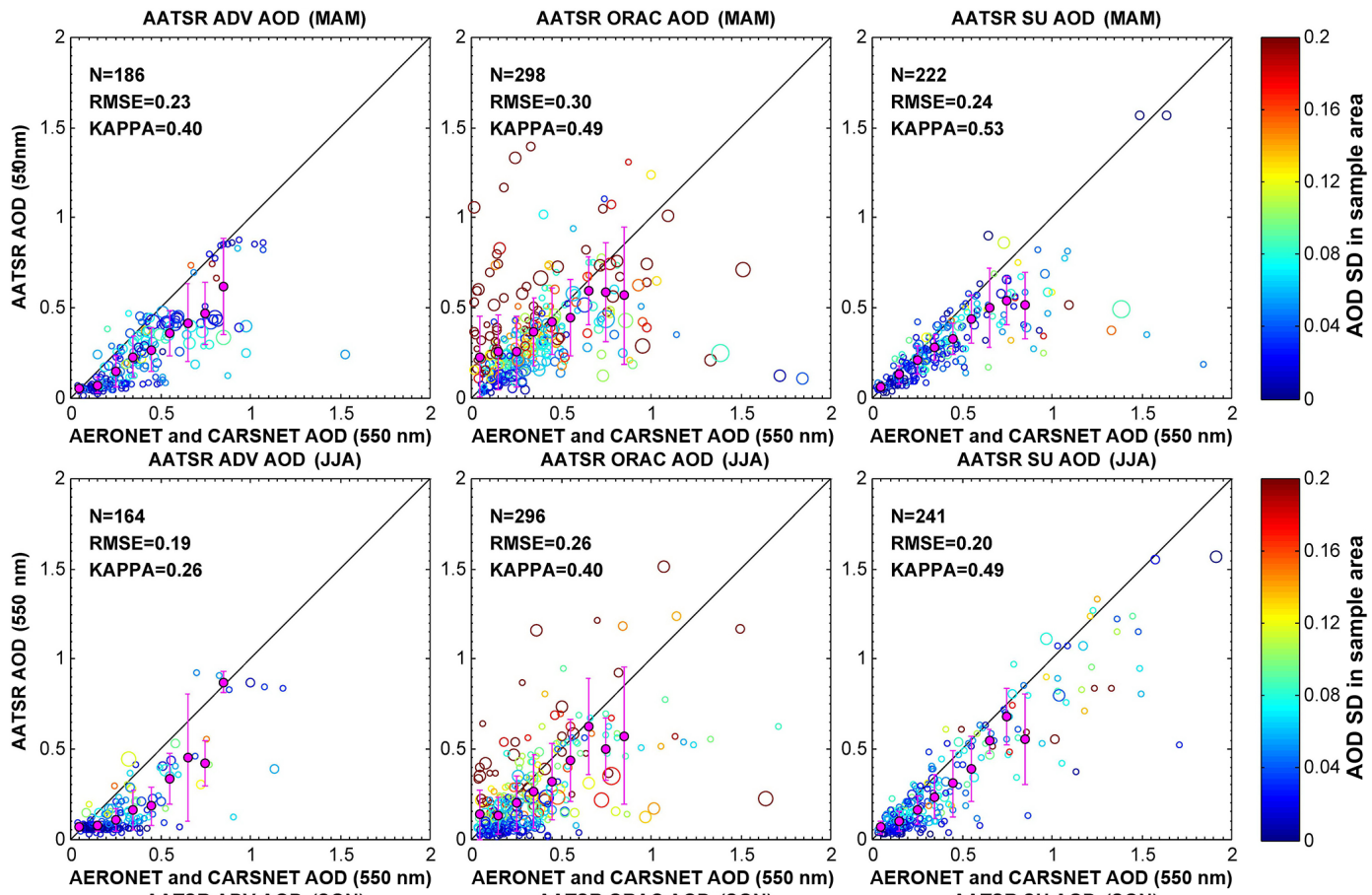

AATSR ORAC AOD (JJA) AATSR SU AOD (JJA)
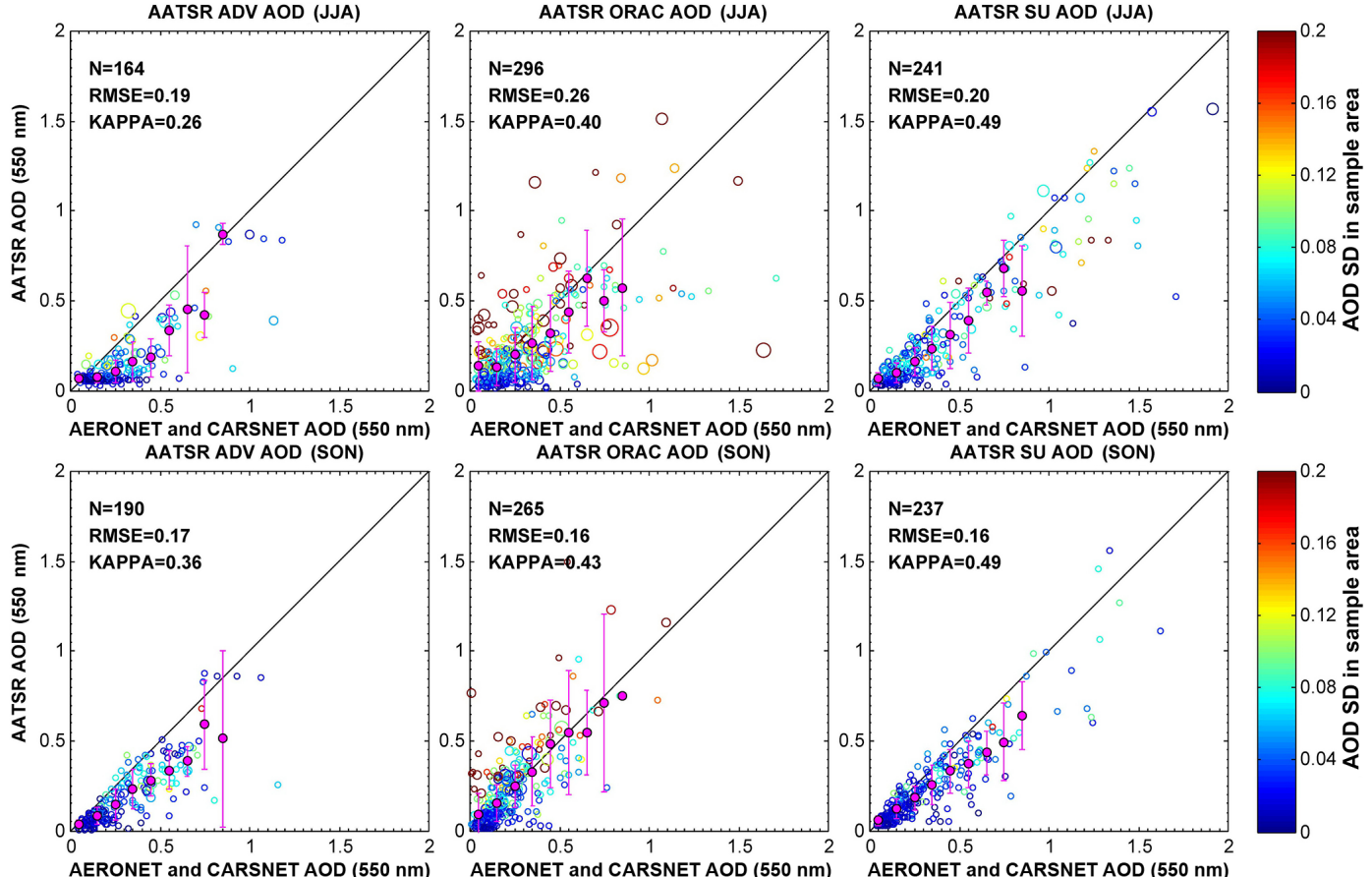

AATSR ORAC AOD (SON)

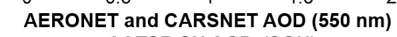

AATSR SU AOD (SON)
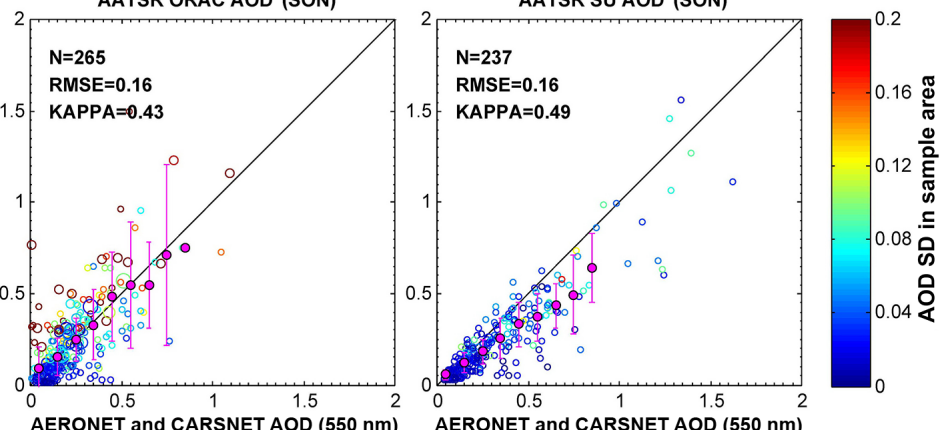

AATSR ORAC AOD (DJF)

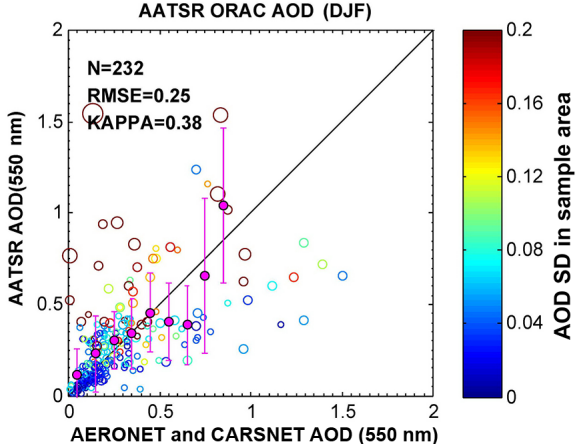

Figure 14. Scatter plots of AATSR ADV, ORAC, and SU L2 AOD products with ground-based data in China in the spring, summer, autumn, and winter time of 2007, 2008, and 2010.

formity in a $50 \mathrm{~km} \times 50 \mathrm{~km}$ area. The best performance on retrieval is in the autumn, with the lowest RMSE being 0.16 and the largest RMB being 0.74 in three seasons shown in Fig. 14. The magenta lines are similar to those of the ADV product in corresponding seasons, showing same level of stability in retrieving AOD. The SU algorithm has no obvious differences in retrieving AOD in three seasons. One limita- tion of the SU and ADV algorithms is less than 30 collocated matches in the winter time so that we cannot evaluate its performance during that time.

The latest MODIS Collection 6 (C6) products were released in 2013, including aerosol datasets produced by two "dark target" (DT) algorithms (one is for retrieving over ocean and the other is for retrieving over land) and the Deep 

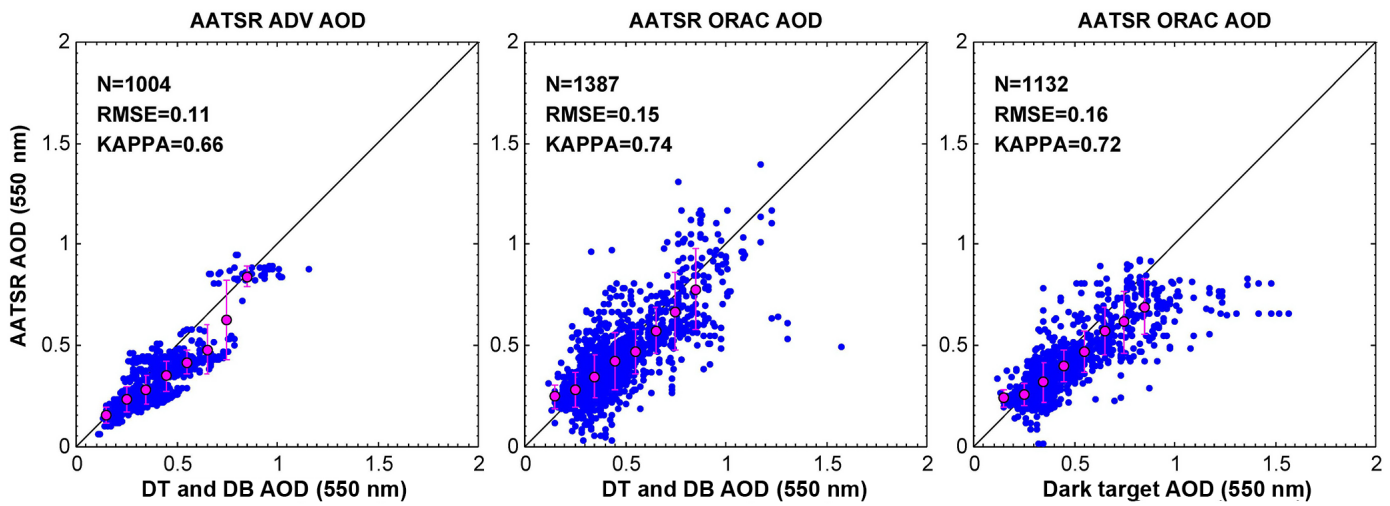

Figure 15. Scatter plot of AATSR AOD and DT and DB AOD.
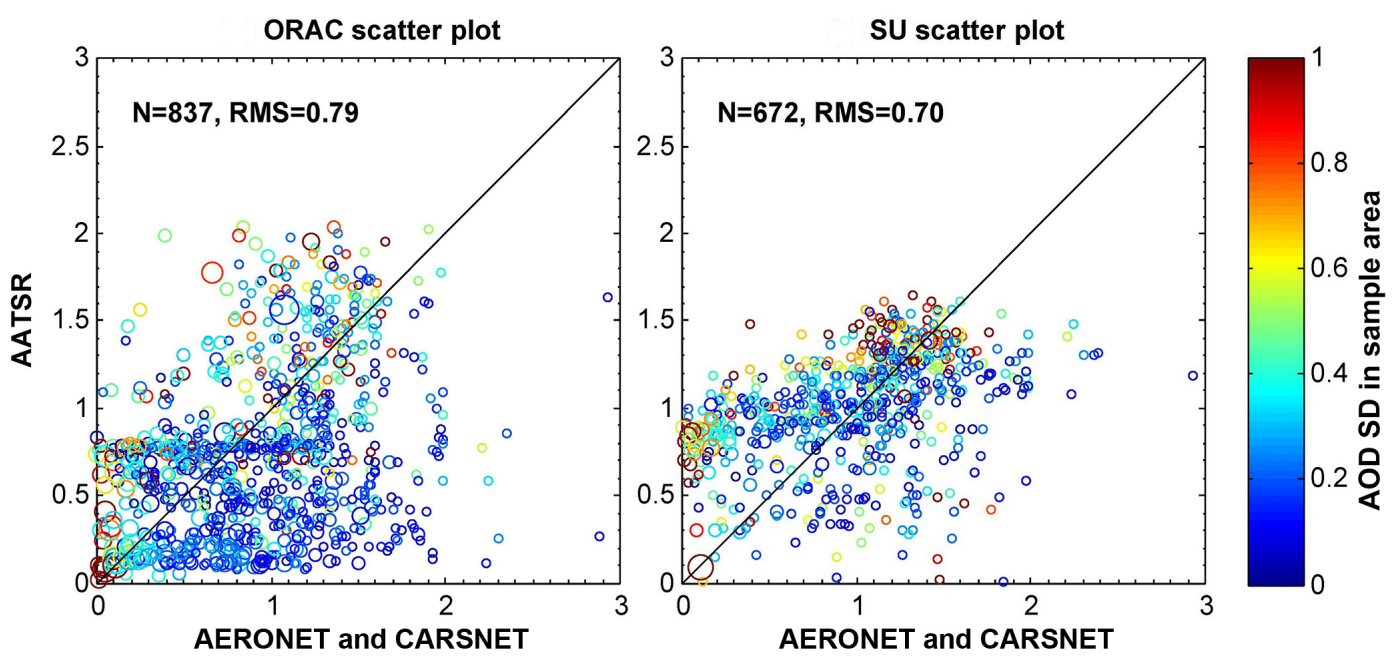

Figure 16. Comparisons of Ångström exponent of ORAC and SU products. The area and colours of bubbles represent AOD uncertainty and AOD values, respectively.

Blue (DB) algorithm for retrieving over bright or semi-arid surface (Levy et al., 2013). For over land, the DT algorithm uses an updated cloud mask to allow the retrieval of heavy aerosol compared to the algorithm employed in MODIS Collection 5. It is reported that MODIS C6 products (produced by three algorithms) are of high quality (Sayer at el., 2014). Here, we select both MODIS C6 DT and DB $10 \mathrm{~km} \times 10 \mathrm{~km}$ merged datasets as reference data for cross-validation of AATSR L2 AOD products. The matches in Fig. 15 are randomly chosen from MODIS and AATSR collocated AOD datasets. The ADV AOD has a lowest RMSE of 0.11. The SU algorithm has the same performance as ORAC (similar RMSE and KAPPA) but with a little underestimation, represented as the magenta line in Fig. 15.

The aerosol Angström exponent is an exponent that expresses the spectral dependence of aerosol optical thickness with the wavelength of incident light (Eck et al., 1999). The Ångström exponent is inversely related to the average size of the particles in the aerosol: the smaller the particles, the larger the exponent. Thus, the Ångström exponent is a useful quantity to assess the particle size of atmospheric aerosols or clouds and the wavelength dependence of the aerosol or cloud optical properties.

The ORAC product provides the Ångström exponent for $550-870 \mu \mathrm{m}$ only and the SU product provides the Angström exponent for $550-870 \mu \mathrm{m}$ only. The CARSNET dataset provides the Ångström exponent for $440-870 \mu \mathrm{m}$ only. As the ADV product provides the Ångström exponent for 550$670 \mu \mathrm{m}$ only, we could not carry out a comparison for the ADV Ångström exponent. We compared the Ångström exponent using both CARSNET and AERONET datasets for SU and ORAC products. Figure 16 shows the comparisons of the Ångström exponent. In general, both the SU and ORAC algorithms generate a similar quality of Ångström exponent values. There is no pattern linking the Ångström exponent with AOD values and uncertainty. 


\section{Conclusions}

Satellite remote sensing of the atmosphere is one important aspect in the PEEX scientific plan. Remotely sensed data could provide continuous spatial coverage of aerosol property over the pan-Eurasian area. These three algorithms (the SU algorithm, the ADV algorithm, and the ORAC algorithm) display different performances in estimating AOD over mainland China in 2007, 2008, and 2010. However, none of the algorithms show an explicitly better performance than the other two. The SU and ADV products have a higher accuracy over most selected sites but less coverage, whereas the ORAC product has greater coverage at the cost of accuracy.

All of these algorithms tend to underestimate AOD to some degree. The underestimation becomes more severe with increasing AOD or aerosol loading. The method of grouping helps to identify possible outliers in different regions of aerosol loading.

The precision of the SU and ADV algorithms is at the same level over different surfaces. However, the SU product has stricter quality control than the ADV product, and it eliminates AODs to make the MBE less than 0.10 over different sites (de Leeuw et al., 2013). Over grassland and barren vegetation, the SU displays a strong performance with slight underestimation $(\mathrm{MBE}<0.10)$. The limitations of underestimation and the applicability of the ADV are more obvious over such sites. For complex surfaces with two or more land cover types, the performances of these three algorithms are at the same level. Note that Lanzhou and Datong are different from other sites, even though the main land cover type is grassland. All of these algorithms underestimated AOD at a high level, perhaps because these algorithms are not sensitive to absorptive aerosols.

Only the ORAC product shows possible outliers identified by Eq. (2), which substantially decreases its accuracy. The most obvious feature of the possible outliers is that the retrieved AODs are higher than the ground-based measurements.

As reference data, AERONET L2 data have some limitations, including the distribution and number of sites in mainland China. Most sites of AERONET are distributed in eastern China and the coastal region of China for special experimental use; as a result, sufficient reference data cannot be obtained to validate the AOD product. The CARSNET data make up for this shortage because there are more CARSNET sites in China, especially in western China, where few AERONET sites have been constructed. Limited both by reference data and satellite retrievals, most co-allocated pairs occur in March to November, and a few occur in winter (December, January, and February).

\section{Data availability}

The ESA Aerosol_cci AOD research data (ADV, ORAC and $\mathrm{SU}$ ) used in this publication are publicly available at http://www.icare.univ-lille1.fr/cci. The MODIS AOD data are available via http://modis-atmos.gsfc.nasa.gov/MOD04_ L2/. AERONET data have been downloaded from http:// aeronet.gsfc.nasa.gov/.

Acknowledgements. This work was supported in part by the Ministry of Science and Technology (MOST) of China under grant nos. 2013CB733403 and 2016YFA0600302, the National Natural Science Foundation of China (NSFC) under grant nos. 41471306 and 41590853, and the EU/FP7 MarcPolo project (Grant Agreement no. 606953). Part of the work was conducted in preparation for the Aerosol_cci project (ESA-ESRIN project AO/1-6207/09/I-LG), from which three AATSR AOD products were provided. The data for uncertainty analysis and validation came from 34 AERONET sites and 8 CARSNET sites. We thank the PIs, investigators, and their staff for establishing and maintaining the data for this study.

Edited by: A. Ding

Reviewed by: two anonymous referees

\section{References}

Adhikary, B., Kulkarni, S., Dallura, A., Tang, Y., Chai, T., Leung, L. R., Qian, Y., Chung, V., Ramanathan, C. E., and Carmichael, G. R.: A regional scale chemical transport modelling of Asian aerosols with data assimilation of AOD observations using optimal interpolation technique, Atmos. Environ., 42, 8600-8615, 2008.

Andreae, M. O. and Rosenfeld, D.: Aerosol-cloud-precipitation interactions, Part 1. The nature and sources of cloud-active aerosols, Earth-Sci. Rev., 89, 13-41, 2008.

Bevan, S., North, P., Los, S., and Grey, W.: A global dataset of atmospheric aerosol optical depth and surface reflectance from AATSR, Remote Sens. Environ., 116, 199-210, 2012.

Bilal, M., J. E. Nichol, and Chan, P. W.: Validation and accuracy assessment of a Simplified Aerosol Retrieval Algorithm (SARA) over Beijing under low and high aerosol loadings and dust storms, Remote Sens. Environ., 153, 50-60, 2014.

Bloch, D. A. and Kraaemer, H. C.: $2 \times 2$ Kappa coefficients: Measures of agreement or association, Biometrics, 45, 269-287, 1989.

Che, H., Zhang, X., Chen, H., Damiri, B., Goloub P., Li, Z., Zhang, X., Wei, Y., Zhou, H., Dong, F., Li, D., and Zhou, T.: Instrument calibration and aerosol optical depth validation of the China Aerosol Remote Sensing Network, J. Geophys. Res., 114, D03206, doi:10.1029/2008JD011030, 2009.

Che, Y., Xue, Y., Xu, H., Mikusauskas, R., and She, L.: The inter-comparison of AATSR aerosol optical depth retrievals from various algorithms, in Proceedings of the IEEE International Geoscience and Remote Sensing Symposium held in Milan, Italy, 27-31 July 2015, 2230-2233, doi:10.1109/IGARSS.2015.7326249, 2015. 
Chu, D. A., Kaufman, Y. J., Ichoku, C., Remer, L. A., Tanré, D., and Holben, B. N.: Validation of MODIS aerosol optical depth retrieval over land, dust, Geophys. Res. Lett., 29, MOD2-1MOD2-4, doi:10.1029/2001GL013205, 2002.

Climate Change Initiative: http://www.esa-aerosol-cci.org/, last access: 15 January 2016.

Cohen, J. A.: A coefficient of agreement for nominal scales, Educ. Psychol. Meas., 20, 37-46, 1960.

de Haan, J. F., Bosma, P. B., and Hovenier, J. W.: The adding method for multiple scattering calculations of polarized light, Astron. Astrophys., 183, 371-391, 1987.

de Leeuw, G., Holzer-Popp, T., Bevan, S., Davies, W. H., Descloitres, J., Grainger, R. G., Griesfeller, J., Heckel, A., Kinne, S., Klüser, L., Kolmonen, P., Litvinov, P., Martynenko, D., North, P., Ovigneur, B., Pascal, N., Poulsen, C., Ramon, D., Schulz, M., Siddans, R., Sogacheva, L., Tanré, D., Thomas, G. E., Virtanen, T. H., von Hoyningen-Huene, W., Vountas, M., and Pinnock, S.: Evaluation of seven European aerosol optical depth retrieval algorithms for climate analysis, Remote Sens. Environ., 162, 295315,2013

Eck, T. F., Holben, B. N., Reid, J. S., Dubovik, O., Smirnov, A., O'Neill, N. T., Slutsker, I., and Kinne, S.: Wavelength dependence of the optical depth of biomass burning, urban, and desert dust aerosols, J. Geophys. Res.-Atmos., 104, 3133331349, 1999.

Flowerdew, R. J. and Haigh, J. D.: Retrieval of aerosol optical thickness over land using the ATSR-2 Dual-Look Satellite Radiometer, Geophys. Res. Lett., 23, 351-354, 1996.

Foody, G. M.: Status of land cover classification accuracy assessment, Remote Sens. Environ., 80, 185-=-201, 2002.

Grey, W. M. E., North, P. R. J., Los, S. O., and Mitchell, R. M.: Aerosol Optical Depth and Land Surface Reflectance from Multiangle AATSR Measurements: Global Validation and Intersensor Comparisons, IEEE T. Geosci. Remote, 44, 2184-2197, 2006.

Griggs, M.: Satellite Observation of Atmospheric Aerosols During the EOMET Cruise, J. Atmos. Sci., 36, 695-698, 1979.

Holben, B. N., Eck, T. F., Slutsker, I., Tanré, D., Buis, J. P., Setzer, K. A., Vermote, E., Reagan, J. A., Kaufman, Y. J., Nakajima, T., Lavenu, F., Jankowiak, I., and Smirnov, A.: AERONET - A Federated Instrument Network and Data Archive for Aerosol Characterization, Remote Sens. Environ., 66, 1-16, 1998.

Holzer-Popp, T., de Leeuw, G., Griesfeller, J., Martynenko, D., Kluser, L., Bevan, S., Davies, W., Ducos, F., Deuze, J. L., Graigner, R. G., von Hoyningen-Huene, W., Kolmonen, P., Litvinov, P., North, P., Poulsen, C. A., Ramon, D., Siddans, R., Sogacheva, L., Tanre, D., Thomas, G. E., Vountas, M., Descloitres, J., Griesfeller, J., Kinne, S., Schulz, M., and Pinnock, S., A.:Aerosol retrieval experiments in the ESA Aerosol_cci project, Atmos. Meas. Tech., 6, 1919-1957, doi:10.5194/amt-61919-2013, 2013.

Ichoku, C, D. A. Chu, Mattoo, S., Kaufman, Y. J., Remer, L. A., Tanré, D., Slutsker, I., and Holben, B. N.: A spatiotemporal approach for global validation and analysis of MODIS aerosol products, Geophys. Res. Lett., 29, MOD1-1-MOD1-4, doi:10.1029/2001GL013206, 2002.

IPCC: Intergovernmental Panel on Climate Change: Climate Change 2013: The Physical Science Basis, Contribution of Working Group I to the Fifth Assessment Report of the IPCC, edited by: Stocker, T. F., Qin, D., Plattner, G. K., Tignor, M., Allen, S. K., Boschung, J., Nauels, A., Xia, Y., Bex, V., an Midgley, P. M., Cambridge University Press, Cambridge, UK, New York, NY, USA, 2013.

Kahn, R. A., Gaitley, B. J., Martonchik, J. V., Diner, D. J., and Crean, K. A.: Multiangle Imaging Spectroradiometer (MISR) global aerosol optical depth validation based on 2 years of coincident Aerosol Robotic Network (AERONET) observations, J. Geophys. Res., 110, D10S04, doi:10.1029/2004JD004706, 2005.

Kahn, R. A., Li, W. H., Moroney, C., Diner, D. J., Martonchik, J. V., and Fishbei, E.: Aerosol source plume physical characteristics from Space-based multiangle imaging, J. Geophys. Res., 112, D11205, doi:10.1029/2006JD007647, 2007.

Kahn, R. A., Nelson, D. L., Garay, M. J., Levy, R. C., Bull, M. A., Diner, D. J., Martonchik, J. V., Paradise, S. R., Hansen, E. G., and Remer, L. A.: MISR aerosol product attributes and statistical comparisons With MODIS, IEEE T. Geosci. Remote, 47, 40954113, 2009.

Kahn, R. A., Garay, M. J., Nelson, D. L., Levy, R. C., Bull, M. A., Diner, D. J., Martonchik, J. V., Hansen, E. L., Remer, L. A., and Tanré, D.: Response to "Ward Unified Satellite Climatology of Aerosol Properties, 3. MODIS versus MISR versus AERONET", J. Quant. Spectrosc. Ra., 112, 901-909, 2011.

Kaufman, Y. J., Tanré, D., Remer, L. A., Vermote, E. F., Chu, A., Holben, B. N.: Operational remote sensing of tropospheric aerosol over land from EOS moderate resolution imaging spectroradiometer, J. Geophys. Res., 102, 17051-17067, 1997.

Kinne, S., Lohmann, U., Feichter, J., Schulz, M., Timmreck, C., Ghan, S., Easter, R., Chin, M., Ginoux, P., Takemura, T., Tegen, I., Koch, D., Herzog, M., Penner, J., Pitari, G., Holben, B., Eck, T., Smirnov, A., Dubovik, O., Slutsker, I., Tanre, D., Torres, O., Mishchenko, M., Geogdzhayev, I., Chu, D. A., and Kaufman, Y.: Monthly averages of aerosol properties: a global comparison among models, satellite data, and AERONET ground data, J. Geophys. Res., 108, 4634, doi:10.1029/2001JD001253, 2003.

Kinne, S., O’Donnel, D., Stier, P., Kloster, S., Zhang, K., Schmidt, H., Rast, S., Giorgetta, M., Eck, T. F., and Stevens, B.: MACv1: A new global aerosol climatology for climate studies, J. Adv. Model Earth Syst., 5, 704-740, 2013.

Kokhanovsky, A. A. and de Leeuw, G.: Satellite Aerosol Remote Sensing Over Land, Springer, Berlin, 2009.

Kolmonen, P., Sogacheva, L., Timo, H., Virtanen, de Leeuw, G., and Kulmala, M.: The ADV/ASV AATSR aerosol retrieval algorithm: current status and presentation of a full-mission AOD dataset, Int. J. Digit. Earth, 9, 545-561, 2016.

Kulmala, M., Alekseychik, P., Paramonov, M., Laurila, T., Asmi, E., Arneth, A., Zilitinkevich, S., and Kerminen, V.-M.: On measurements of aerosol particles and greenhouse gases in Siberia and future research needs, Boreal Env. Res., 16, 337-362, 2011.

Kulmala, M., Lappalainen, H. K., Petäjä, T., Kurten, T., Kerminen, V.-M., Viisanen, Y., Hari, P., Sorvari, S., Bäck, J., Bondur, V., Kasimov, N., Kotlyakov, V., Matvienko, G., Baklanov, A., Guo, H. D., Ding, A., Hansson, H.-C., and Zilitinkevich, S.: Introduction: The Pan-Eurasian Experiment (PEEX) multidisciplinary, multiscale and multicomponent research and capacity-building initiative, Atmos. Chem. Phys., 15, 1308513096, doi:10.5194/acp-15-13085-2015, 2015.

Levy, R. C., Remer, L. A., and Dubovik, O.: Global aerosol optical properties and application to Moderate Resolution Imaging 
Spectroradiometer aerosol retrieval over land, J. Geophys. Res., 112, D13210, doi:10.1029/2006JD007815, 2007.

Levy, R. C., Remer, L. A., Kleidman, R. G., Mattoo, S., Ichoku, C., Kahn, R., and Eck, T. F.: Global evaluation of the Collection 5 MODIS dark-target aerosol products over land, Atmos. Chem. Phys., 10, 10399-10420, doi:10.5194/acp-10-10399-2010, 2010.

Levy, R. C., Mattoo, S., Munchak, L. A., Remer, L. A., Sayer, A. M., Patadia, F., and Hsu, N. C.: The Collection 6 MODIS aerosol products over land and ocean, Atmos. Meas. Tech., 6, 29893034, doi:10.5194/amt-6-2989-2013, 2013.

Li, M. and Zhang, L.: Haze in China: Current and future challenges, Environ. Pollut., 189, 85-86, 2014.

Martonchik, J. V., Diner, D. J., Kahn, R., and Gaitley, B.: Comparison of MISR and AERONET aerosol optical depths over desert sites, Geophys. Res. Lett., 31, L16102, doi:10.1029/2004GL019807, 2004.

McMurry, P. H.: A review of atmospheric aerosol measurements, Atmos. Environ., 34, 1959-1999, 1999.

Mei, L., Xue, Y., Xu. H., Guang, J., Li, Y., Wang, Y., Ai, J., Jiang, S., And He, X.: Validation and analysis of aerosol optical thickness retrieval over land, Int. J. Remote Sens., 33, 781-803, 2012.

Misra, A., Jayaraman, A., and Ganguly, D.: Validation of MODIS derived aerosol optical depth over Western India, J. Geophys. Res., 113, D04203, doi:10.1029/2007JD009075, 2008.

North, P. R. J., Briggs, S. A., Plummer, S. E., and Settle, J. J.: Retrieval of land surface bidirectional reflectance and aerosol opacity from ATSR-2 multiangle imagery, IEEE T. Geosci. Remote, 37, 526-537, 1999.

Prins, E. M., Feltz, J. M., Menzel, W. P., Menzel, W. P., and Ward, D. E.: An overview of GOES-8 diurnal fire and smoke results for SCAR-B and 1995 fire season in South America, J. Geophys. Res., 103, 31821-31836, 1998.

Remer, L. A., Kaufman, Y. J., Tanré, D., Mattoo, S., Chu, D. A., Martins, J. V., Li, R.-R., Ichoku, C., Levy, R. C., Kleidman, R. G., Eck, T. F., Vermote, E., and Holben, B. N.: The MODIS aerosol algorithm, products, and validation, J. Atmos. Sci., 62, 947-973, 2005.

Rosenfield, G. H. and Fitzpatrick-Lins, K.: A coefficient of agreement as a measure of thematic classification accuracy, Photogramm. Eng. Rem. S., 52, 223-227, 1986.
Samet, J. M., Dominici, F., Curriero, F. C., Coursac, I., and Zeger, S. L.: Fine particulate air pollution and mortality in 20 US cities, 1987-1994, New Engl. J. Med., 343, 1742-1749, 2000.

Sayer, A. M., Munchak, L. A., Hsu, N. C., Levy, R. C., Bettenhausen, C., and Jeong, M.-J., MODIS Collection 6 aerosol products: Comparison between Aqua's e-Deep Blue, Dark Target, and "merged" data sets, and usage recommendations, J. Geophys. Res.-Atmos., 119, 13965-13989, 2014.

Stehman, S. V.: Selecting and interpreting measures of thematic classification accuracy, Remote Sens. Environ., 62, 77-89, 1997.

Takahashi, Y., Higashi, M., Furukawa, T., and Mitsunobu, S.: Change of iron species and iron solubility in Asian dust during the long-range transport from western China to Japan, Atmos. Chem. Phys., 11, 11237-11252, doi:10.5194/acp-1111237-2011, 2011.

Thomas, G. E., Carboni, E., Sayer, A. M., Poulsen, C. A., Siddans, R., and Grainger, R. G.: Oxford-RAL Aerosol and Cloud (ORAC): Aerosol Retrievals from Satellite Radiometers, in: Aerosol Remote Sensing Over Land, edited by: Kokhanovsky, A. and de Leeuw, G., Springer, Berlin, 2009.

Torres, O., Bhartia, P. K., Herman, J. R., Sinyuk, A., Ginoux, P., and Holben, B.: A long-term record of aerosol optical depth from TOMS observations and comparison to AERONET measurements, J. Atmos. Sci., 59, 398-413, 2002.

Tzanis, C. and Varotsos, C. A.: Tropospheric aerosol forcing of climate: a case study for the greater area of Greece, Int. J. Remote Sens., 29, 2507-2517, 2008.

Varotsos, C.: Airborne measurements of aerosol, ozone, and solar ultraviolet irradiance in the troposphere, J. Geophys. Res., 110, D09202, doi:10.1029/2004JD005397, 2005

Varotsos, C., Ondov, J., Tzanis, C., Ozturk, F., Nelson, M., Ke, H., and Christodoulakis, J.: An observational study of the atmospheric ultra-fine particle dynamics, Atmos. Environ., 59, 312 319, 2012.

Veefkind, J. P., de Leeuw, G., and Durkee, P. A.: Retrieval of aerosol optical depth over land using two-angle view satellite radiometry during TARFOX, Geophys. Res. Lett, 25, 3135-3138, 1998.

Xue, Y., Xu, H., Guang, J., Mei, L., Guo, J., Li, C., Mikusauskas, R., and He, X.: Observation of an agricultural biomass burning in central and east China using merged aerosol optical depth data from multiple satellite missions, Int. J. Remote Sens., 35, 59715983, 2014. 